\title{
Comparison of chemical lateral boundary conditions for air quality predictions over the contiguous United States during pollutant intrusion events
}

\author{
Youhua Tang ${ }^{1,2}$, Huisheng Bian ${ }^{3,4}$, Zhining Tao ${ }^{3,5}$, Luke D. Oman ${ }^{3}$, Daniel Tong ${ }^{2,10}$, Pius Lee ${ }^{1}$, Patrick C. Campbell ${ }^{1,2}$, \\ Barry Baker ${ }^{1,2}$, Cheng-Hsuan Lu ${ }^{6,7}$, Li Pan $^{8,9}$, Jun Wang ${ }^{8}$, Jeffery McQueen ${ }^{8}$, and Ivanka Stajner ${ }^{8}$ \\ ${ }^{1}$ NOAA Air Resources Laboratory, College Park, MD, USA \\ ${ }^{2}$ Center for Spatial Information Science and Systems, George Mason University, Fairfax, VA, USA \\ ${ }^{3}$ NASA Goddard Space Flight Center, Greenbelt, MD, USA \\ ${ }^{4}$ University of Maryland, Baltimore County, Baltimore, MD, USA \\ ${ }^{5}$ Universities of Space Research Association, Columbia, MD, USA \\ ${ }^{6}$ Atmospheric Sciences Research Center, University at Albany, State University of New York, Albany, NY, USA \\ ${ }^{7}$ Joint Center for Satellite Data Assimilation, Boulder, CO, USA \\ ${ }^{8}$ NOAA NCEP Environmental Modeling Center, College Park, MD, USA \\ ${ }^{9}$ I. M. Systems Group Inc., Rockville, MD, USA \\ ${ }^{10}$ Department of Atmospheric, Oceanic \& Earth Sciences, George Mason University, Fairfax, VA, USA
}

Correspondence: Youhua Tang (youhua.tang@noaa.gov)

Received: 11 June 2020 - Discussion started: 5 August 2020

Revised: 6 January 2021 - Accepted: 17 January 2021 - Published: 19 February 2021

\begin{abstract}
The National Air Quality Forecast Capability (NAQFC) operated in the US National Oceanic and Atmospheric Administration (NOAA) provides the operational forecast guidance for ozone and fine particulate matter with aerodynamic diameters less than $2.5 \mu \mathrm{m}\left(\mathrm{PM}_{2.5}\right)$ over the contiguous 48 US states (CONUS) using the Community Multi-scale Air Quality (CMAQ) model. The existing NAQFC uses climatological chemical lateral boundary conditions (CLBCs), which cannot capture pollutant intrusion events originating outside of the model domain. In this study, we developed a model framework to use dynamic CLBCs from the Goddard Earth Observing System Model, version 5 (GEOS) to drive NAQFC. A mapping of the GEOS chemical species to CMAQ's CB05-AERO6 (Carbon Bond 5; version 6 of the aerosol module) species was developed. The utilization of the GEOS dynamic CLBCs in NAQFC showed the best overall performance in simulating the surface observations during the Saharan dust intrusion and Canadian wildfire events in summer 2015. The simulated $\mathrm{PM}_{2.5}$ was improved from 0.18 to 0.37 , and the mean bias was reduced from -6.74 to $-2.96 \mu \mathrm{g} \mathrm{m}^{-3}$ over
\end{abstract}

CONUS. Although the effect of CLBCs on the $\mathrm{PM}_{2.5}$ correlation was mainly near the inflow boundary, its impact on the background concentrations reached further inside the domain. The CLBCs could affect background ozone concentrations through the inflows of ozone itself and its precursors, such as CO. It was further found that the aerosol optical thickness (AOT) from satellite retrievals correlated well with the column CO and elemental carbon from GEOS. The satellite-derived AOT CLBCs generally improved the model performance for the wildfire intrusion events during a summer 2018 case study and demonstrated how satellite observations of atmospheric composition could be used as an alternative method to capture the air quality effects of intrusions when the CLBCs of global models, such as GEOS CLBCs, are not available.

\section{Introduction}

The chemical lateral boundary conditions (CLBCs) are pivotal to the prediction accuracy of regional chemical transport 
models (CTMs) (Tang et al., 2007, 2009). The CLBCs represent the spatiotemporal distribution of species concentrations along the lateral boundaries of the domain of a regional model. CLBCs can be either static or dynamic in type and can significantly affect CTMs predictions. One effect is imposing a constraint with static background concentrations for long-lived pollutants, such as $\mathrm{CO}$ and $\mathrm{O}_{3}$, which is the typical role of climatological CLBCs for non-intrusion events. For example, regional models like the Community Air Quality Multi-scale Model (CMAQ) hemispheric version (Mathur et al., 2017) utilizes static CLBCs that constrain chemical concentrations along the Equator. The influences of external pollutant intrusion events can only be achieved with dynamic (time-varying) CLBCs. Such CLBCs can come from a global model, a regional model that uses a larger domain (Tang et al., 2007), or observed profiles (Tang et al., 2009). Henderson et al. (2014) compiled a 10-year CLBCs database over the contiguous United States (CONUS) using a global chemical transport model (GEOS-Chem, Goddard Earth Observing System Model, Bey et al., 2001) and evaluated it against satellite-retrieved ozone and $\mathrm{CO}$ vertical profiles.

The US National Oceanic and Atmospheric Administration's (NOAA) National Air Quality Forecast Capability (NAQFC), which is currently based on the regional-scale CMAQ model, requires CLBCs for its daily prediction. The current NAQFC uses the dust-only aerosol CLBCs from the NOAA Environmental Modeling System (NEMS) Global Forecast System (GFS) Aerosol Component (NGAC) (Lu et al., 2016; Wang et al., 2018), which is an inline global model coupled with the Goddard Chemistry Aerosol Radiation and Transport (GOCART) aerosol mechanism (Chin et al., 2000, 2002; Colarco et al., 2010). Prior to the implementation of the NGAC CLBCs, NAQFC used the background, static aerosol profiles for the aerosol CLBCs (Lee et al., 2017). For the gaseous species, NAQFC uses modified monthly averaged CLBCs from a 2006 GEOS-Chem simulation (Pan et al., 2014). To alleviate surface ozone overpredictions, the upper-tropospheric ozone CLBCs from GEOSChem have been limited to $\leq 100$ ppbv (parts per billion by volume).

Static CLBCs cannot capture the signals of some intrusion events, such as the biomass burning plumes from the outside of the domain, which could affect the prediction of ozone and particulate matter with aerodynamic diameter less than $2.5 \mu \mathrm{m}\left(\mathrm{PM}_{2.5}\right)$. For non-intrusion events, Tang et al. (2007) investigated the sensitivity of regional CTMs to CLBCs and found that the background magnitude of the pollutant concentrations was more important than the variation of the CLBCs for the near-surface prediction over polluted areas. Over the contiguous USA, the northern and western USA are near to the prevailing inflow lateral boundaries where Canadian emissions and long-range transported Asian air masses can affect the chemical background concentrations. Additionally, the southern and eastern boundaries are subjected to the Saharan dust intrusions during the summer, which may result in surface $\mathrm{PM}_{2.5}$ concentration increases (Lu et al., 2016). CLBCs from global models are needed to fully assess such impacts of intrusion events and to advance the operational NAQFC. In this study, we extracted the CLBCs from the GEOS global chemical circulation model (Strode et al., 2019; Molod et al., 2012) in both static (monthly average) and dynamic (every $3 \mathrm{~h}$ ) modes. The NAQFC runs using both GEOS and NGAC CLBCs are compared to a NAQFC base case with monthly 2006 GEOS-Chem CLBCs for summer 2015. During this period, the Canadian wildfires and Sahara dust storms affected the CONUS domain's northern and southern regions, respectively. In addition, we investigate the method of using satellite-derived CLBCs for pollutant intrusion events when CLBCs of global models may not be available.

\section{Model configuration and experiment design}

The operational NAQFC is based on CMAQ version 5.0.2, driven by meteorological forecasts from NOAA and NCEP's (National Centers for Environmental Prediction) North American Mesoscale Model (NAM). The CMAQ configuration includes the CB05 (Carbon Bond 5) gaseous chemical mechanism (Yarwood et al., 2005) with updated toluene (Whitten et al., 2010) and chlorine chemistry (CB05tucl) (Tanaka et al., 2003; Sarwar et al., 2007) and AERO6 (Carlton et al., 2010; Foley et al., 2010; Sonntag et al., 2014), version 6 of the aerosol module, driven by NOAA and NCEP's North American Mesoscale Model (NAM) forecasting. It has a $12 \mathrm{~km} \times 12 \mathrm{~km}$ horizontal resolution covering CONUS, with 35 vertical layers up to $100 \mathrm{hPa}$. Anthropogenic area and mobile emissions are based on the on the 2011 US EPA (Environmental Protection Agency) National Emissions Inventory (NEI2011v2), and the point source emissions have been updated with the US EPA Continuous Emission Monitoring System (CEMS) for the prediction year (2015). Biogenic emissions are based on the Biogenic Emission Inventory System (BEIS) 3.14 (Pierce et al., 1998). Wildfire emissions originating inside the CONUS domain are estimated using the US Forest Service (USFS) BlueSky fire emissions estimation algorithm, in which the fire location information is provided by the NOAA Hazard Mapping System (HMS). The NOAA HMS is a satellite-based fire detection system that includes manual quality control. The detailed wildfire emission process of this system has been described in Pan et al. (2020).

In this study, we conducted five model runs with different CLBCs (Table 1) over the CONUS domain (Fig. 1). The first run is the NAQFC-CMAQ base case (referred to as CMAQ_Base), which uses the modified GEOS-CHEM 2006 monthly gaseous CLBCs and clean aerosol background. The CMAQ_Base CLBCs were used in the earlier NAQFC system before NGAC was made available. The second run, NGAC-LBC, is the same as in CMAQ_Base for gaseous 
Table 1. The runs with different lateral boundary conditions (LBCs) conducted in this study. EC: elemental carbon; POC: primary organic carbon.

\begin{tabular}{llll}
\hline Runs & Aerosol LBCs & Gaseous LBCs & Temporal resolution \\
\hline CMAQ_Base & Static clean background & $\begin{array}{l}\text { Static GEOS-Chem 2006 } \\
\text { with } \mathrm{O}_{3} \leq 100 \mathrm{ppbv}\end{array}$ & Static monthly mean \\
\hline GEOS-LBC & Dynamic full aerosol & Dynamic full chemistry & $3 \mathrm{~h}$ \\
\hline GLBC-Monthly & $\begin{array}{l}\text { Monthly mean full } \\
\text { aerosol }\end{array}$ & $\begin{array}{l}\text { Monthly mean full } \\
\text { chemistry }\end{array}$ & Static monthly mean \\
\hline NGAC-LBC & $\begin{array}{l}\text { Dynamic GOCART } \\
\text { simple aerosol }\end{array}$ & Same as CMAQ_Base & $3 \mathrm{~h}$ \\
\hline AOT-NLBC & $\begin{array}{l}\text { Daily AOT-derived } \\
\text { northern LBC (NLBC) } \\
\text { for EC and POC }\end{array}$ & $\begin{array}{l}\text { Daily AOT-derived } \\
\text { northern LBC for CO, } \\
\text { NO }\end{array}$, PAN, and HNO & $\begin{array}{l}\text { 24h for derived NLBC; } \\
\text { static monthly mean } \\
\text { for all others }\end{array}$ \\
\hline
\end{tabular}

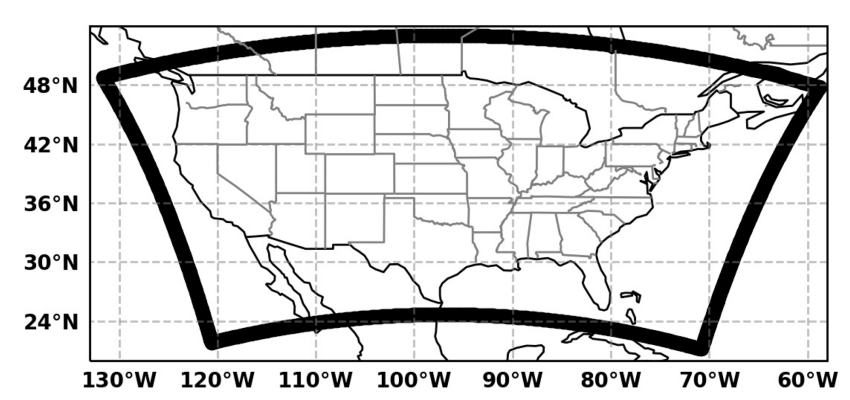

Figure 1. NAQFC CONUS domain (outlined in bolded black). This figure is plotted using cartopy https://scitools.org.uk/cartopy/docs/ latest/ (last access: February 2021), which uses the national and state border information from http://www.naturalearthdata.com/ (last access: February 2021). Please note that the above figure contains incomplete US state borders.

CLBCs but uses NGAC's dynamic aerosol CLBCs. The third run, the GEOS-LBC simulation, uses GEOS dynamic CLBCs and has full chemistry and dynamic variation for both gaseous and aerosol species, while the four-run GLBCMonthly tests the GEOS monthly mean CLBCs to gauge the impacts of the CLBCs' temporal variability. The fifth and final run incorporates satellite-based aerosol optical thickness (AOT) for the northern CLBCs (AOT-NLBC). The AOTNLBC run is the same as the GEOS-Monthly run, except that its northern boundary condition is generated from the relationship of VIIRS (Visible Infrared Imaging Radiometer Suite) AOT and GEOS-LBC for the wildfire intrusion events, which will be described later.

The extraction of the GEOS CLBCs for NAQFC's domain boundaries is based on the existing global-to-regional interface tool developed by Tang et al $(2007,2009)$ for MOZART (Model for Ozone and Related chemical Tracers), RAQMS (Realtime Air Quality Modeling System), and NGAC global models with additional enhancements to support GEOS's NetCDF4 format, vertical layers, and chemical species. This tool includes two major functions: spatial mapping and species mapping. Spatially, GEOS's concentrations from its $576 \times 361$ grid in a $0.625^{\circ} \times 0.5^{\circ}$ horizontal resolution with 72 vertical layers are three-dimensionally interpolated into CMAQ's CONUS lateral boundary periphery in a $12 \mathrm{~km}$ horizontal resolution. The species mapping is also needed due to the different chemical mechanisms employed in GEOS and CMAQ, as discussed in the following sections.

\subsection{Gaseous species mapping}

The GEOS outputs 122 gaseous chemical species and 15 aerosol species. For species such as $\mathrm{O}_{3}, \mathrm{CO}, \mathrm{NO}$, and $\mathrm{NO}_{2}$, an explicit one-to-one mapping can be achieved. However, some volatile organic compounds (VOCs) need special treatment during the conversions, as GEOS uses different lumping approaches compared to what is done in CMAQ CB05tucl (Carbon Bond 5 mechanism with toluene and chloride species). Table 2 lists the VOC species mapping used to convert GEOS's gaseous species to CMAQ's CB05tucl species. Two methods were employed for mapping the VOC species: one was based on the carbon bond structure, e.g., ALK4 $\rightarrow 4$ PAR (Table 2), and the other was based on the similarity of the reactions. In GEOS, for example, the products of the isoprene reaction with $\mathrm{NO}_{3}$ are lumped into $\mathrm{INO}_{2}$, an intermediate $\mathrm{RO}_{2}$ radical.

$\mathrm{ISOP}+\mathrm{NO}_{3} \rightarrow \mathrm{INO}_{2}$

The radical $\mathrm{INO}_{2}$ participates in the following reactions (Eastham et al., 2014; Tyndall et al., 2001):

$$
\begin{aligned}
\mathrm{INO}_{2} & +\mathrm{NO} \rightarrow 1.10 \mathrm{NO}_{2}+0.80 \mathrm{HO}_{2}+0.85 \mathrm{HN}_{3} \\
& +0.05 \mathrm{NO}_{2}+0.10 \mathrm{MACR}+0.15 \mathrm{CH}_{2} \mathrm{O} \\
& +0.05 \mathrm{MVK}, \\
\mathrm{INO}_{2} & +\mathrm{HO}_{2} \rightarrow \mathrm{INPN},
\end{aligned}
$$


Table 2. VOC (volatile organic compound) species mapping table from GEOS to CMAQ CB05tucl.

\begin{tabular}{|c|c|}
\hline GEOS species (mole) & CMAQ species (mole) \\
\hline $\mathrm{HCOOH}$ & FACD (formic acid) \\
\hline $\mathrm{MO}_{2}\left(\mathrm{CH}_{3} \mathrm{O}_{2}\right)$ & $\mathrm{XO}_{2}$ \\
\hline MP (methylhydroperoxide) & MEPX \\
\hline $\mathrm{A}_{3} \mathrm{O}_{2}$ (primary $\mathrm{RO}_{2}$ from $\mathrm{C}_{3} \mathrm{H}_{8}: \mathrm{CH}_{3} \mathrm{CH}_{2} \mathrm{CH}_{2} \mathrm{OO}$ ) & $\mathrm{PAR}+X \mathrm{O}_{2}$ \\
\hline ACTA (acetic acid) & $\mathrm{AACD}$ \\
\hline $\mathrm{ATO}_{2}\left(\mathrm{RO}_{2}\right.$ from acetone: $\left.\mathrm{CH}_{3} \mathrm{C}(\mathrm{O}) \mathrm{CH}_{2} \mathrm{O}_{2}\right)$ & $2 \cdot \mathrm{PAR}+\mathrm{XO}_{2}$ \\
\hline $\mathrm{B}_{3} \mathrm{O}_{2}$ (secondary $\mathrm{RO}_{2}$ from $\mathrm{C}_{3} \mathrm{H}_{8}: \mathrm{CH}_{3} \mathrm{CH}(\mathrm{OO}) \mathrm{CH}_{3}$ ) & $2 \cdot \mathrm{B}_{3} \mathrm{O}_{2}$ \\
\hline ALK4 $\left(\mathrm{C}_{4}\right.$ or higher alkanes) & $4 \cdot \mathrm{PAR}$ \\
\hline $\mathrm{C}_{3} \mathrm{H}_{8}$ & $1.5 \cdot \mathrm{PAR}+\mathrm{NR}$ \\
\hline $\mathrm{ETO}_{2}$ (ethylperoxy radical: $\mathrm{CH}_{3} \mathrm{CH}_{2} \mathrm{OO}$ ) & $\mathrm{MEO}_{2}+\mathrm{PAR}$ \\
\hline ETP (ethylhydroperoxide: $\mathrm{CH}_{3} \mathrm{CH}_{2} \mathrm{OOH}$ ) & $\mathrm{MEPX}+\mathrm{PAR}$ \\
\hline $\mathrm{GCO}_{3}$ (hydroxy peroxyacetyl radical: $\mathrm{HOCH}_{2} \mathrm{C}(\mathrm{O}) \mathrm{OO}$ ) & $\mathrm{C}_{2} \mathrm{O}_{3}$ \\
\hline GLYX (glyoxal) & FORM + PAR \\
\hline GLYC (glycolaldehyde: $\mathrm{HOCH}_{2} \mathrm{CHO}$ ) & $\mathrm{FORM}+2 \cdot \mathrm{PAR}$ \\
\hline GP (peroxide from $\mathrm{GCO}_{3}: \mathrm{HOCH}_{2} \mathrm{C}(\mathrm{O}) \mathrm{OOH}$ ) & $\mathrm{ROOH}$ \\
\hline GPAN (peroxyacylnitrate: $\mathrm{HOCH}_{2} \mathrm{C}(\mathrm{O}) \mathrm{OONO}_{2}$ ) & PANX \\
\hline $\mathrm{HAC}$ (hydroxyacetone: $\mathrm{HOCH}_{2} \mathrm{C}(\mathrm{O}) \mathrm{CH}_{3}$ ) & $2 \cdot \mathrm{PAR}$ \\
\hline IALD (hydroxy carbonyl alkenes from isoprene) & ISOPX \\
\hline $\mathrm{IAO}_{2}\left(\mathrm{RO}_{2}\right.$ from isoprene oxidation products) & $\mathrm{ISOPO}_{2}$ \\
\hline IAP (peroxide from $\mathrm{IAO}_{2}$ ) & $\mathrm{ROOH}$ \\
\hline $\mathrm{INO}_{2}\left(\mathrm{RO}_{2}\right.$ from ISOP $\left.+\mathrm{NO}_{3}\right)$ & $0.2 \cdot \mathrm{ISPD}+0.8 \cdot \mathrm{NTR}+X \mathrm{O}_{2}+0.8 \cdot \mathrm{HO}_{2}+0.2 \cdot \mathrm{NO}_{2}+0.8 \cdot \mathrm{ALDX}+2.4 \cdot \mathrm{PAR}^{\prime}$ \\
\hline INPN (peroxide from $\mathrm{INO}_{2}$ ) & $0.2 \cdot \mathrm{ISPD}+0.8 \cdot \mathrm{NTR}+\mathrm{ROOH}+0.8 \cdot \mathrm{H}_{2} \mathrm{O}_{2}+0.2 \cdot \mathrm{PNA}+0.8 \cdot \mathrm{ALDX}+2.4 \cdot \mathrm{PAR}$ \\
\hline ISN1 $\left(\mathrm{RO}_{2}\right.$ from isoprene nitrate) & NTRI \\
\hline ISNP (peroxide from ISN1) & $\mathrm{NTRIO}_{2}$ \\
\hline $\mathrm{KO}_{2}\left(\mathrm{RO}_{2}\right.$ from $\mathrm{C}_{3}$ or higher ketones $)$ & $X \mathrm{O}_{2}+\mathrm{PAR}$ \\
\hline MACR (methacrolein) & ISPD \\
\hline MAN2 $\left(\mathrm{RO}_{2}\right.$ from MACR $\left.+\mathrm{NO}_{3}\right)$ & $0.925 \cdot \mathrm{HO}_{2}+0.075 \cdot X \mathrm{O}_{2}$ \\
\hline $\mathrm{MAO}_{3}$ (peroxyacyl from MVK + MACR) & $\mathrm{MACO}_{3}$ \\
\hline MAOP (peroxide from $\mathrm{MAO}_{3}$ ) & ISPD \\
\hline MAP (peroxyacetic acid: $\left.\mathrm{CH}_{3} \mathrm{C}(\mathrm{O}) \mathrm{OOH}\right)$ & PACD \\
\hline $\mathrm{MCO}_{3}$ (peroxyacetyl radical) & $\mathrm{C}_{2} \mathrm{O}_{3}$ \\
\hline $\operatorname{MEK}\left(\mathrm{C}_{3}\right.$ or higher ketones $)$ & $4 \cdot \mathrm{PAR}$ \\
\hline $\mathrm{MRO}_{2}\left(\mathrm{RO}_{2}\right.$ from $\left.\mathrm{MACR}+\mathrm{OH}\right)$ & $0.713 \cdot \mathrm{XO}_{2}+0.503 \cdot \mathrm{HO}_{2}$ \\
\hline MRP (Peroxide from $\left.\mathrm{MRO}_{2}\right)$ & $\mathrm{ROOH}$ \\
\hline MVK (methylvinylketone) & ISPD \\
\hline MVN2 $\left(\mathrm{RO}_{2}\right.$ from $\left.\mathrm{MVK}+\mathrm{NO}_{3}\right)$ & $0.925 \cdot \mathrm{HO}_{2}+0.075 \cdot X \mathrm{O}_{2}$ \\
\hline PMN (peroxymethacryloyl nitrate) & OPEN \\
\hline $\mathrm{PO}_{2}\left(\mathrm{RO}_{2}\right.$ from propene $)$ & $\mathrm{XO}_{2}$ \\
\hline $\mathrm{PP}$ (peroxide from $\mathrm{PO}_{2}: \mathrm{HOC}_{3} \mathrm{H}_{6} \mathrm{OOH}$ ) & $\mathrm{ROOH}$ \\
\hline PPN (peroxypropionyl nitrate) & PANX \\
\hline PRN1 $\left(\mathrm{RO}_{2}\right.$ from propene $\left.+\mathrm{NO}_{3}\right)$ & $\mathrm{XO}_{2}$ \\
\hline PRPE (propene) & $\mathrm{OLE}+\mathrm{PAR}$ \\
\hline PRPN (peroxide from PRN1) & $\mathrm{ROOH}$ \\
\hline $\mathrm{R} 4 \mathrm{~N} 1\left(\mathrm{RO}_{2}\right.$ from $\mathrm{C}_{4}+\mathrm{C}_{5}$ alkylnitrates $)$ & $\mathrm{ROOH}+2=\cdot \mathrm{PAR}$ \\
\hline $\mathrm{R} 4 \mathrm{O} 2\left(\mathrm{RO}_{2}\right.$ from $\mathrm{C}_{4}$ alkane $)$ & $X \mathrm{O}_{2}$ \\
\hline R4P (peroxide from R4O2) & $\mathrm{ROOH}$ \\
\hline RA3P (peroxide from $\mathrm{A}_{3} \mathrm{O}_{2}$ ) & $\mathrm{ROOH}$ \\
\hline $\mathrm{RB} 3 \mathrm{P}$ (Peroxide from $\mathrm{B}_{3} \mathrm{O}_{2}$ ) & $\mathrm{ROOH}$ \\
\hline $\mathrm{RCHO}\left(\mathrm{C}_{3}\right.$ or higher aldehydes $)$ & ALDX \\
\hline $\mathrm{RCO} 3$ (peroxypropionyl radical: $\mathrm{CH}_{3} \mathrm{CH}_{2} \mathrm{C}(\mathrm{O}) \mathrm{OO}$ ) & $\mathrm{XO}_{2}$ \\
\hline $\mathrm{RCOOH}\left(\mathrm{C}_{2}\right.$ or higher organic acids $)$ & AACD \\
\hline $\mathrm{RIO} 1$ ( $\mathrm{RO}_{2}$ from isoprene oxidation products) & ISPD \\
\hline $\mathrm{RIO} 2\left(\mathrm{RO}_{2}\right.$ from isoprene $)$ & $\mathrm{ISOPO}_{2}$ \\
\hline RIP (Peroxide from $\mathrm{RIO}_{2}$ ) & ISOPX \\
\hline $\mathrm{ROH}\left(\mathrm{C}_{2}\right.$ or higher alcohols $)$ & $3 \cdot$ PAR \\
\hline $\mathrm{RP}$ (peroxide from $\mathrm{RCO}_{3}$ ) & $\mathrm{ROOH}$ \\
\hline $\mathrm{VRO}_{2}\left(\mathrm{RO}_{2}\right.$ from $\left.\mathrm{MVK}+\mathrm{OH}\right)$ & $\mathrm{ISOPO}_{2}$ \\
\hline VRP (peroxide from $\mathrm{VRO}_{2}$ ) & $\mathrm{ROOH}$ \\
\hline ACET (acetone) & $3 \cdot \mathrm{PAR}$ \\
\hline
\end{tabular}




$$
\begin{aligned}
\mathrm{INO}_{2} & +\mathrm{MO}_{2} \rightarrow 0.55 \mathrm{NO}_{2}+0.40 \mathrm{HO}_{2}+0.425 \mathrm{HNO}_{3} \\
& +0.025 \mathrm{NO}_{2}+0.05 \mathrm{MACR}+0.08 \mathrm{CH}_{2} \mathrm{O} \\
& +0.03 \mathrm{MVK}+0.25 \mathrm{RCHO}+0.75 \mathrm{CH}_{2} \mathrm{O} \\
& +0.25 \mathrm{MOH}+0.25 \mathrm{ROH}+0.05 \mathrm{HO}_{2}, \\
\mathrm{INO}_{2} & +\mathrm{MCO}_{3} \rightarrow \mathrm{MO}_{2}+0.10 \mathrm{NO}_{2}+0.80 \mathrm{HO}_{2} \\
& +0.85 \mathrm{HNO}_{3}+0.05 \mathrm{NO}_{2}+0.10 \mathrm{MACR} \\
& +0.15 \mathrm{CH}_{2} \mathrm{O}+0.05 \mathrm{MVK}, \\
\mathrm{INO}_{2} & +\mathrm{MCO}_{3} \rightarrow \text { RCHO }+ \text { ACTA }+\mathrm{NO}_{2} .
\end{aligned}
$$

The CB05tucl mechanism skips the intermediate $\mathrm{INO}_{2}$ and directly represents it as

$$
\begin{aligned}
\mathrm{ISOP} & +\mathrm{NO}_{3} \rightarrow 0.200 \cdot \mathrm{ISPD}+0.800 \cdot \mathrm{NTR}+\mathrm{XO}_{2} \\
& +0.800 \cdot \mathrm{HO}_{2}+0.200 \cdot \mathrm{NO}_{2}+0.800 \cdot \mathrm{ALD} X \\
& +2.400 \cdot \mathrm{PAR} .
\end{aligned}
$$

Therefore, the GEOS $\mathrm{INO}_{2}$ species is split into seven CB05tucl species with the corresponding factors, respectively (Table 2). This conversion is just an approximation, and a perfect consistency for mapping these species can not be achieved due to the large differences between these two mechanisms, especially in regards to the complexity of isoprene chemistry. Fortunately, for the CONUS domain, the isoprene chemistry influence on the CONUS CLBCs are less significant when compared to the major intrusion events from wildfire plumes and dust storms. Most biogenically emitted species are short-lived, and their direct impact on CLBCs is relatively weak. A similar situation can also be applied to other short-lived species, such as $\mathrm{NO}_{x}$, which will be discussed later. Biogenic emissions can affect local photochemical processes, however, and subsequently generate relatively long-lived species, such as ozone and NTR. Such species may originate from outside the regional domain and thus have impacts on CLBCs and downstream chemistry. This issue is mitigated by the fact that most of these secondary long-lived species are explicitly included in both GEOS and CMAQ chemical mechanisms and can be directly mapped.

Other gaseous species are represented explicitly in the GEOS model, such as methylvinylketone (MVK), which is lumped in the CB05tucl's isoprene product (ISPD). In GEOS, the MVK mainly comes from isoprene, which is consistent with the CMAQ's ISPD source. Some GEOS species can also be mapped to CB05tucl species based on their carbon bonds, e.g., R4N2 (GEOS's $\mathrm{C}_{4-5}$ alkyl nitrates), which can be mapped to NTR + 2.0 PAR in the CB05tucl mechanism. Some of the mapping treatments, such as the ALK4 $\left(\mathrm{C}_{4}\right.$ or higher alkanes) conversion to four paraffin carbon bonds (Table 2), may have a "truncation error", as it only counted butane isomers. The effect of this truncation error, however, is likely relatively minor for CONUS CLBCs. The GEOS global model also mainly treats ALK4 as butane or $\mathrm{C}_{n}$, where $n \sim 4$. Although GEOS's ALK4 emission includes some $\mathrm{C}_{5}$ or higher $\left(\mathrm{C}_{5}^{+}\right)$alkanes, the relatively shorter lifetime of $\mathrm{C}_{5}^{+}$alkanes (Helmig et al., 2014) makes them harder to reach CONUS from their major upstream sources, such as East Asia. In this study, wildfire emissions may contribute to the $\mathrm{C}_{5}^{+}$alkane's impacts on the CONUS CLBCs, but these $\mathrm{C}_{5}^{+}$emissions are at least 1 order of magnitude lower than the corresponding wildfire $\mathrm{CO}$, ethane, and propane emissions (Urbanski et al., 2008). Moreover, the impacts of the complex chemistry mapping on the CLBCs for the pollutant intrusion events (mainly wildfire events) are not expected to be significant for the ozone and $\mathrm{PM}_{2.5}$ predictions in this study, since the constituents of the major wildfire intrusion from the GEOS global model are $\mathrm{CO}, \mathrm{NO}_{x}$, ethane, propane, elemental carbon (EC), and organic carbon (OC).

\subsection{Aerosol species mapping}

The GEOS model uses an updated GOCART aerosol scheme (Bian et al., 2017), compared to NGAC GOCART (Colarco et al., 2010, respectively), which includes additional species of ammonium and nitrates in three size bins (NO3an1, NO3an2, and NO3an3). Table 3 lists the aerosol species mapping from GEOS aerosols to CMAQ AERO6 species used in this study. GEOS aerosols have fixed size bins defined by their diameters, while CMAQ aerosols use three size modes, Aitken (ATKN), accumulations (ACC), and coarse (COR), or alternatively $i, j$, and $k$ modes, respectively (Appel et al., 2010). Each of these size modes has its own lognormal size distribution (Whitby and McMurry, 1997). To convert the aerosol species from GEOS to CMAQ's AERO6, we need to consider not only the aerosol composition and the GEOS size bins conversion to the CMAQ size modes but also the size distribution within each CMAQ size mode that is controlled by the CMAQ aerosol number concentrations (the third column of Table 3). GEOS's dust aerosols are mapped to AOTHRJ (other unreactive aerosols in the accumulation mode) and ASOIL (soil particles in the coarse mode) in CMAQ. Although the CMAQ AERO6 has explicit elemental ions such as $\mathrm{Ca}$ and $\mathrm{Mg}$, which are possible dust ingredients, we do not consider the reaction effects due to these ions. Tang et al. (2004) studied the dust outflow during the ACE-Asia (Asian Pacific Regional Aerosol Characterization Experiment) field experiment and found that only a small portion of cations in dust particles was available for aerosol uptake and reactions and that this portion is negligible for aged dust air masses.

\section{Case studies for the summer 2015}

During summer 2015, two intrusion events occurred, one in the southeastern USA and one in the northern USA, respectively. The southeastern intrusion was due to the long-range transported-dust storm from the Sahara. The northern intrusion was due to a Canadian wildfire event and its southward transport into the United States. Figure 2 shows the Suomi 
Table 3. Aerosol species mapping table from GEOS to CMAQ AERO6 (“ $D$ ” represents the diameter of the GEOS aerosol bin).

\begin{tabular}{lll}
\hline GEOS aerosol $\left(\mu \mathrm{g} \mathrm{m}^{-3}\right)$ & $\begin{array}{l}\text { CMAQ aerosol mass } \\
\text { concentration }\left(\mu \mathrm{m}^{-3}\right)\end{array}$ & $\begin{array}{l}\text { CMAQ aerosol number } \\
\text { concentration }\left(\text { no. } \mathrm{m}^{-3}\right)\end{array}$ \\
\hline BCPHILIC & AECJ & $2.72 \times 10^{7}(\mathrm{ACC})$ \\
BCPHOBIC & AECJ & $2.72 \times 10^{7}(\mathrm{ACC})$ \\
OCPHILIC & APOCJ & $2.72 \times 10^{7}(\mathrm{ACC})$ \\
OCPHOBIC & APOCJ & $2.72 \times 10^{7}(\mathrm{ACC})$ \\
SO4 & ASO4J & $2.72 \times 10^{7}(\mathrm{ACC})$ \\
NH4a & ANH4J & $2.72 \times 10^{7}(\mathrm{ACC})$ \\
NO3an1 $($ mean $D: 0.5 \mu \mathrm{m})$ & ANO3J & $2.72 \times 10^{7}(\mathrm{ACC})$ \\
NO3an2 $($ mean $D: 4.2 \mu \mathrm{m})$ & $0.8 \cdot$ ANO3J $+0.2 \cdot$ ANO3K & $5.4 \times 10^{6}(\mathrm{ACC})+1.2 \times 10^{4}(\mathrm{COR})$ \\
NO3an2 $($ mean $D: 15 \mu \mathrm{m})$ & ANO3K & $6 \times 10^{3}(\mathrm{COR})$ \\
DU001 $(D: 0.2-2 \mu \mathrm{m})$ & AOTHRJ & $2.72 \times 10^{7}(\mathrm{ACC})$ \\
DU002 $(D: 2-3.6 \mu \mathrm{m})$ & $0.45 \cdot$ AOTHRJ $+0.55=\cdot$ ASOIL & $3.3 \times 10^{5}(\mathrm{ACC})+5.1 \times 10^{4}(\mathrm{COR})$ \\
DU003 $(D: 3.6-6 \mu \mathrm{m})$ & ASOIL & $1.15 \times 10^{4}(\mathrm{COR})$ \\
DU004 $(D: 6-12 \mu \mathrm{m})$ & $0.75 \cdot$ ASOIL & $1.4 \times 10^{3}(\mathrm{COR})$ \\
SS001 $(D: 0.06-0.2 \mu \mathrm{m})$ & $0.39 \cdot$ ANAI $+0.61 \cdot$ ACLI & $7.4 \times 10^{8}(\mathrm{ATKN})$ \\
SS002 $(D: 0.2-1 \mu \mathrm{m})$ & $0.39 \cdot$ ANAJ $+0.61 \cdot$ ACLJ & $2.72 \times 10^{7}(\mathrm{ACC})$ \\
SS003 $(D: 1-3 \mu \mathrm{m})$ & $0.312 \cdot$ ANAJ $+0.488 \cdot$ ACLJ $+0.078 \cdot$ ASEACAT $+0.122 \cdot$ ACLK & $1.7 \times 10^{5}(\mathrm{ACC})+1.26 \times 10^{4}(\mathrm{COR})$ \\
SS004 $(D: 3-10 \mu \mathrm{m})$ & $0.39 \cdot$ ASEACAT $+0.61 \cdot$ ACLK & $1.36 \times 10^{4}(\mathrm{COR})$ \\
\hline
\end{tabular}

NPP (National Polar-orbiting Partnership) satellite's VIIRS AOT retrieval from later June to early July in 2015 and highlights these two intrusion events.

\subsection{Dust storm events in summer 2015}

As shown in Fig. 2, a dust storm originating from the Sahara reached the southeastern USA via transatlantic transport. The two global models, GEOS and NGAC, captured this dust intrusion and increased the aerosol CLBCs of NAQFC. Figure 3 shows the corresponding three CLBCs for ASOIL and AOTHRJ along the model's boundaries on 2 July 2015. With the exception of CMAQ_Base, all the other three CLBCs showed enhanced ASOIL (the coarse-mode dust) and AOTHRJ (the accumulation-mode dust) near the domain's southeastern corner and the south-central boundary. GLBC-Monthly represents the monthly average of GEOSLBC for July 2015 and has the lowest increments for the two types of aerosols. The two dynamic CLBCs, GEOS-LBC and NGAC-LBC, showed similar aerosol increments along the domain boundaries. However, the NGAC aerosols tended to have a broader spread than those of GEOS-LBC, especially for ASOIL, which could reach above an altitude of $10 \mathrm{~km}$ with concentrations greater than $5 \mu \mathrm{g} \mathrm{m}^{-3}$ (Fig. 3e). NGACLBC also showed enhanced dust signals over the western boundary, where GEOS-LBC did not show any dust-related aerosols. Another difference between these two CLBCs was their ratio of AOTHRJ versus ASOIL. The dynamic NGACLBC had higher ASOIL, the coarse-mode dust, than that of GEOS-LBC (Fig. 3a and e), but its AOTHRJ was lower than the latter (Fig. $3 b$ and $\mathrm{f}$ ). This is particularly true over the south-central boundary, where GEOS-LBC had AOTHRJ up to $30 \mu \mathrm{g} \mathrm{m}^{-3}$. It implies that besides their difference in transport patterns, these two global models also had some differences in their dust size distributions.

Figure 4 shows comparisons of the simulated $\mathrm{PM}_{2.5}$ concentrations against the observations from the US EPA AIRNow stations. CMAQ_Base represented a clear background situation and has obviously missed this dust intrusion event and underestimated the $\mathrm{PM}_{2.5}$ over the southern and southeastern United States. The two dynamical CLBCs, GEOS-LBC and NGAC-LBC, captured the intrusion signals well and yielded the best model performance. While both GEOS-LBC and NGAC-LBC underpredicted $\mathrm{PM}_{2.5}$ over central Florida, their performance was improved compared to CMAQ_Base. Further downwind over Texas, GEOS-LBC yielded more widespread and higher $\mathrm{PM}_{2.5}$ enhancements compared to NGAC-LBC and agreed better with the observations (except for the overpredictions over northern Texas). GLBC-Monthly run had a moderate $\mathrm{PM}_{2.5}$ enhancement but still underestimated the dust intrusion, falling between CMAQ_Base and two dynamic CLBC cases in magnitude of $\mathrm{PM}_{2.5}$ enhancements. Figure 5 shows a similar story for the scenario of $3 \mathrm{~d}$ later. GEOS-LBC yielded the best overall model performance, although it still underpredicted the $\mathrm{PM}_{2.5}$ concentration over Florida and northern Texas.

A time-series comparison over Florida and Texas showed that, in general, the best models regarding performance in capturing the dust intrusion are, in order, GEOS-LBC, NGAC-LBC, GLBC-Monthly, and CMAQ_Base (Fig. 6). An exception, however, is NGAC-LBC's underprediction for $\mathrm{PM}_{2.5}$ concentrations over Florida in June. These comparisons demonstrate the advantage of using dynamic CLBCs for capturing intrusion events. The dynamic CLBCs (GEOS- 

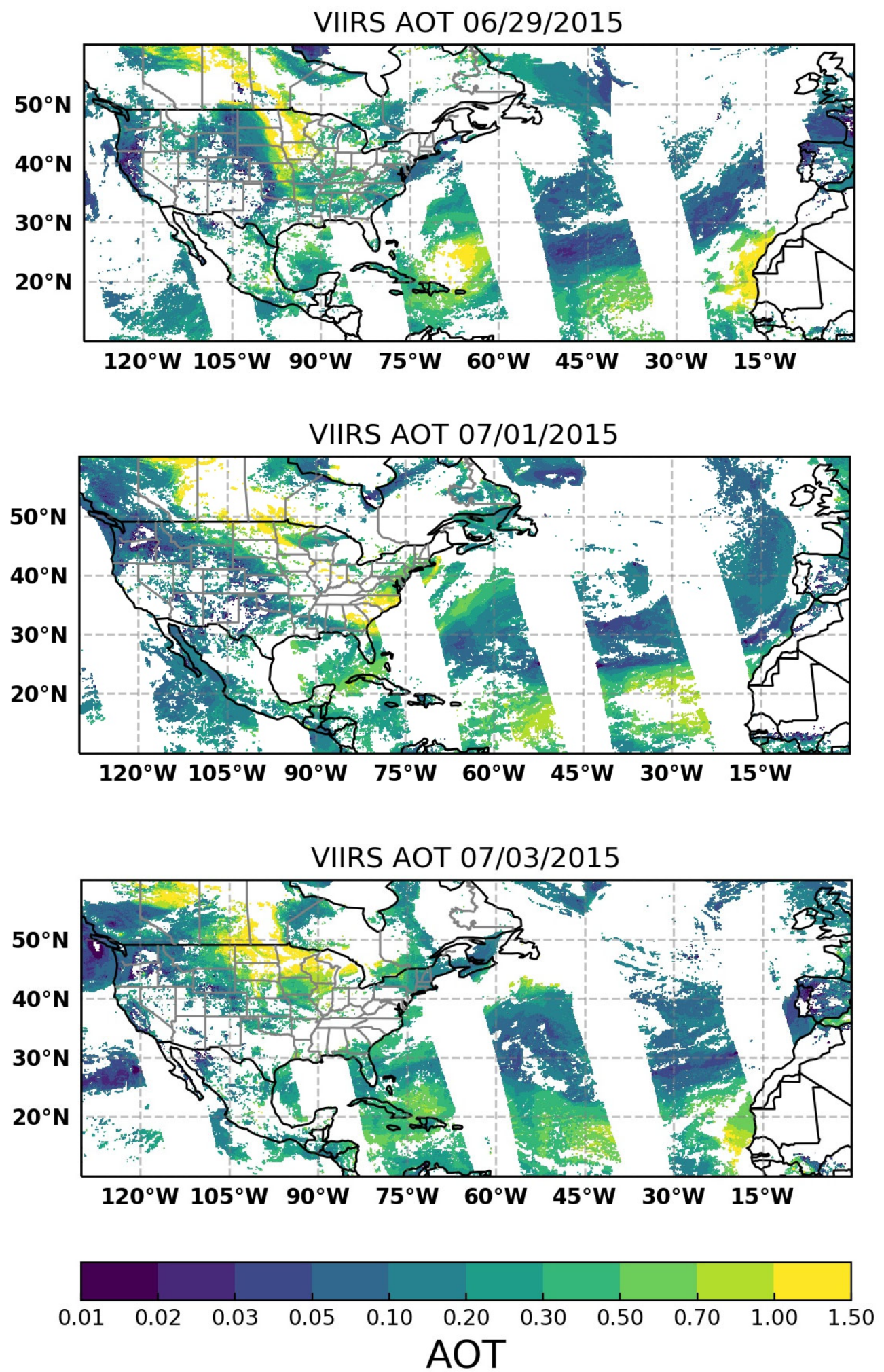

Figure 2. Suomi NPP VIIRS aerosol optical thickness (AOT) on 29 June, 1 July, and 3 July 2015. Please note that the dates in this figure are given in the format of month day year (mm/dd/yyyy). This figure is plotted using cartopy https://scitools.org.uk/cartopy/docs/latest/ (last access: February 2021), which uses the national and state border information from http://www.naturalearthdata.com/ (last access: February 2021). Please note that the above figure contains incomplete US state borders and disputed territories. 
(a) GEOS ASOIL Lateral Boundary Condition at 22Z, 07/02/2015

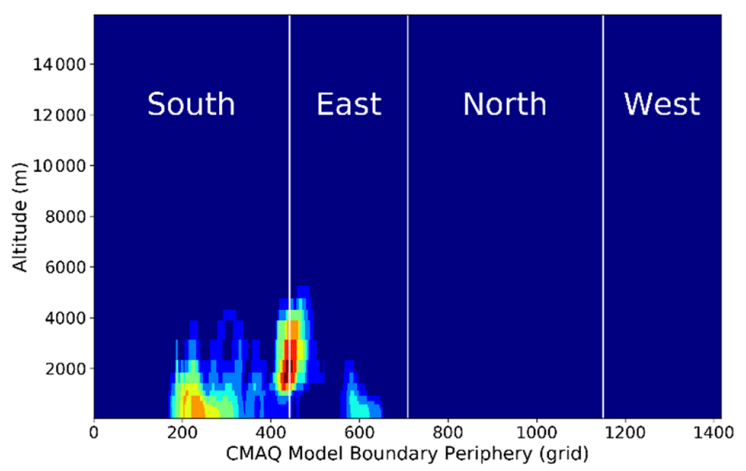

(c) GLBC-Monthly ASOIL Lateral Boundary Condition For July, 2015

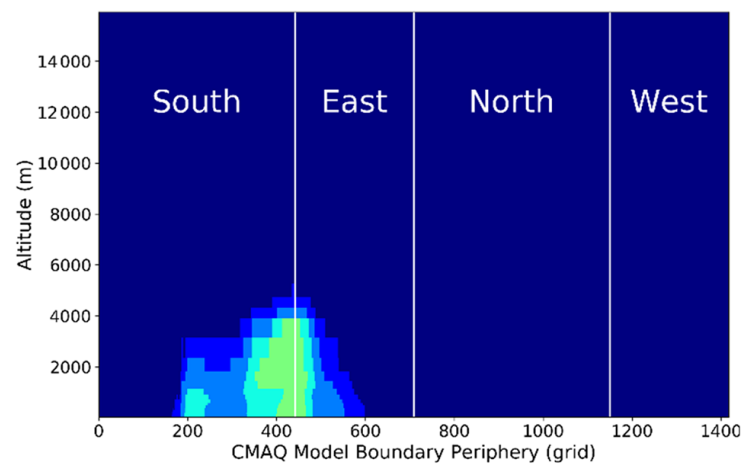

(e) NGAC ASOIL Lateral Boundary Condition at 21Z, 07/02/2015

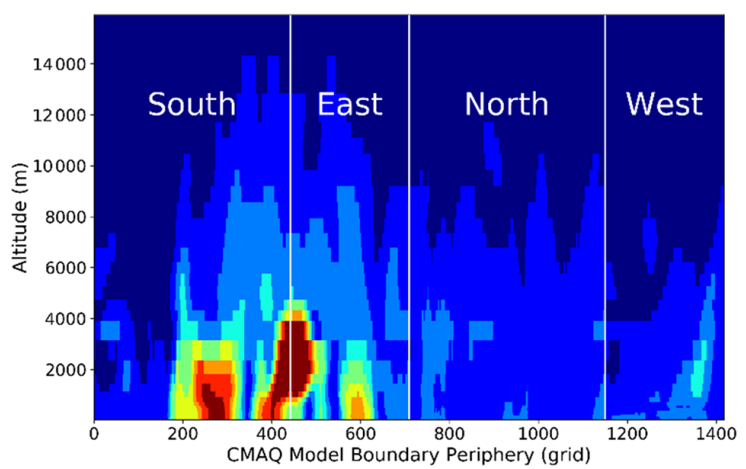

(b)

GEOS AOTHRJ Lateral Boundary Condition at 22Z, 07/02/2015

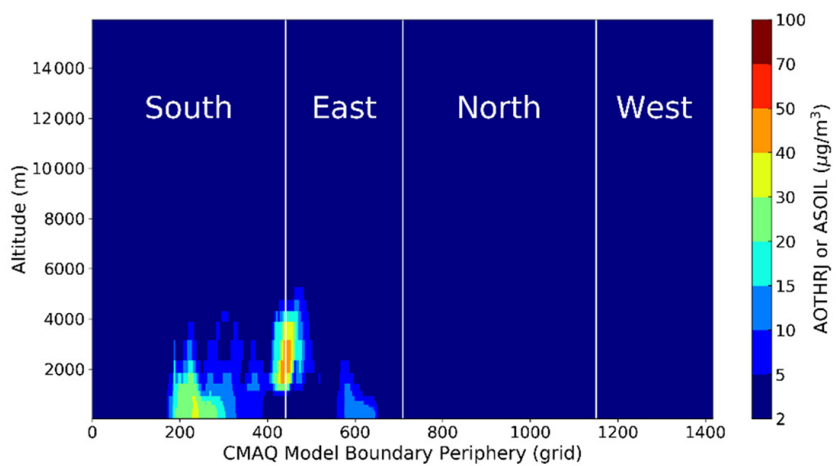

(d) GLBC-Monthly AOTHRJ Lateral Boundary Condition For July, 2015

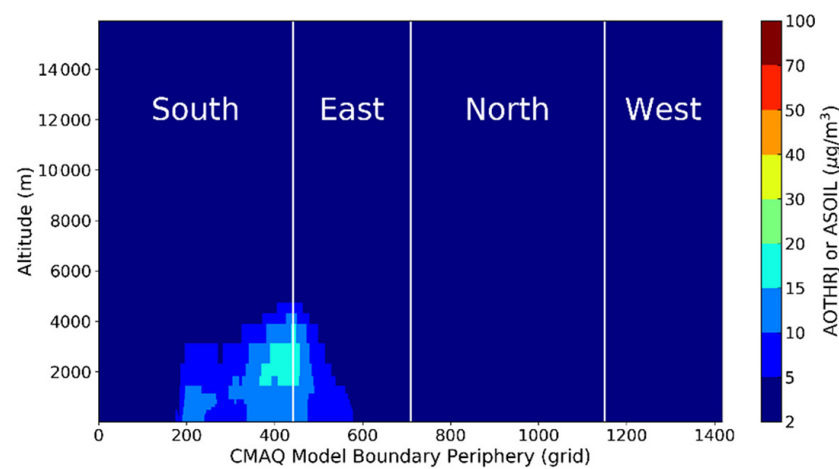

(f) NGAC AOTHRJ Lateral Boundary Condition at 21Z, 07/02/2015

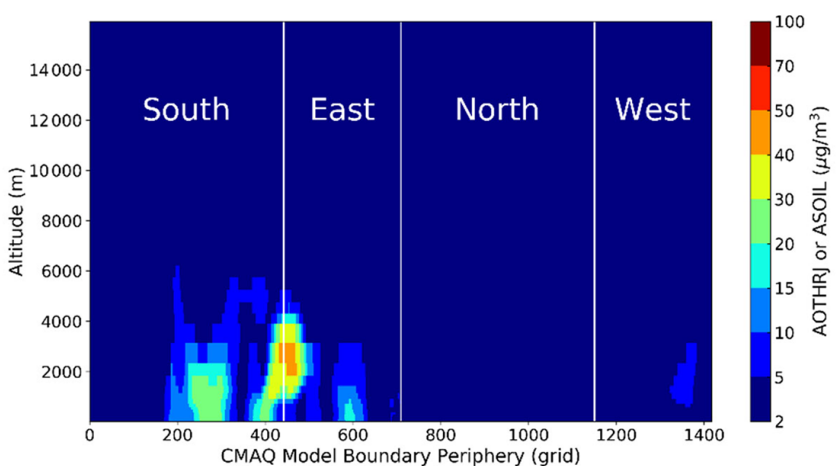

Figure 3. The lateral boundary conditions for ASOIL (a, c, e) and AOTHRJ (b, d, f) along the domain periphery for 2 July 2015 . The CMAQ LBC's grid index for each LBC segment is always from south to north and then from west to east, so the LBC index's start points are reset instead of being continuous for the north and west boundaries. Please note that the dates in this figure are given in the format of month day year $(\mathrm{mm} / \mathrm{dd} / \mathrm{yyyy})$.

LBC and NGAC-LBC) still missed some intrusion peaks, such as the one on 30 June over Texas, and also showed disagreement with the observed temporal variability, e.g., 1 July over Florida and 8 July over Texas. It should be noted that the nighttime $\mathrm{PM}_{2.5}$ spike on 4 July (5 July in UTC) was not related to the dust intrusion but was caused by US Independence Day's fireworks. This firework emission was not included in our anthropogenic emission inventory. Most firework emissions were injected in elevated levels, and the as- sociated pollutants could be transported to extended downstream areas. If the downstream areas were relatively big, its regional averaged effect could appear for a longer time. This is the reason why some $\mathrm{PM}_{2.5}$ concentration spikes that started on 4 July could last longer than the firework emission durations, e.g., $1 \mathrm{~h}$. 
(a) CMAQ Base Predicted $\mathrm{PM}_{2.5}$ at $18 \mathrm{Z}, 07 / 02 / 2015$

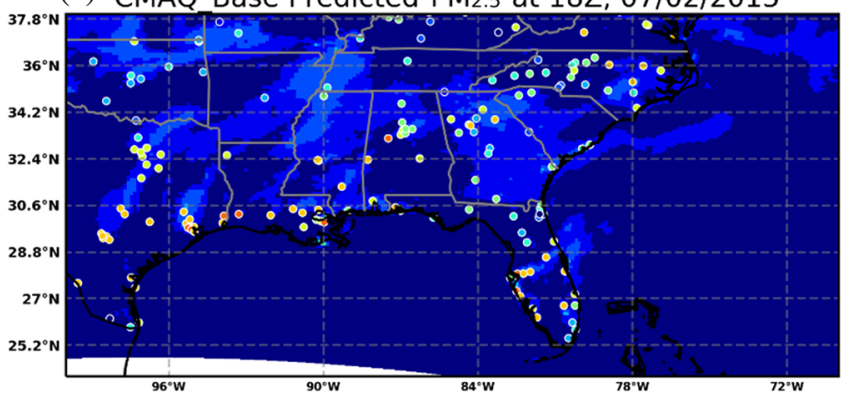

(c) GLBC-Monthly Predicted $\mathrm{PM}_{2.5}$ at $18 \mathrm{Z}, 07 / 02 / 2015$

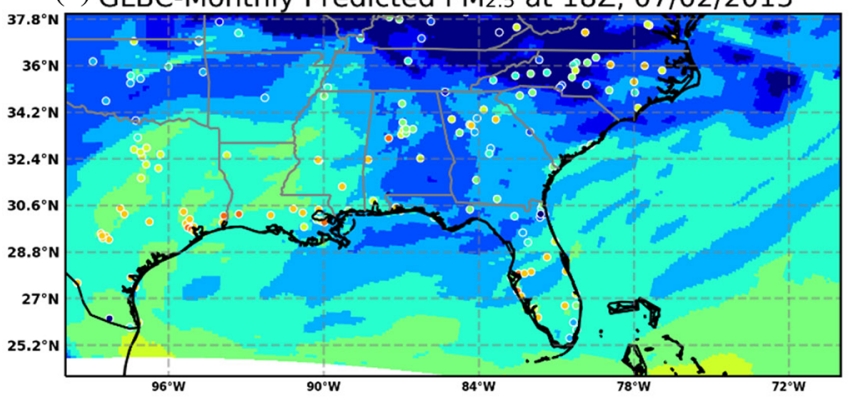

(b) GEOS5-LBC Predicted $\mathrm{PM}_{2.5}$ at $18 \mathrm{Z}, 07 / 02 / 2015$

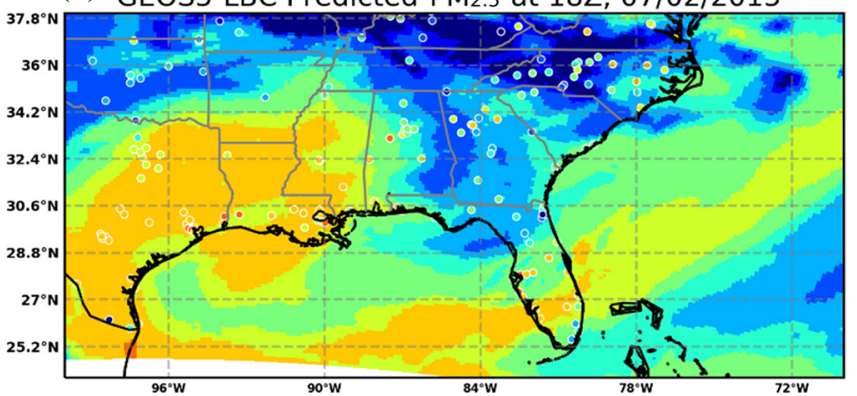

(d) NGAC-LBC Predicted $\mathrm{PM}_{2.5}$ at $18 \mathrm{Z}, 07 / 02 / 2015$

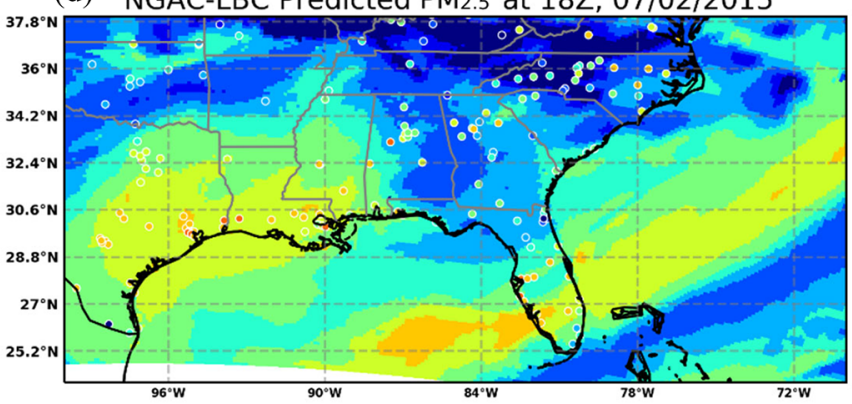

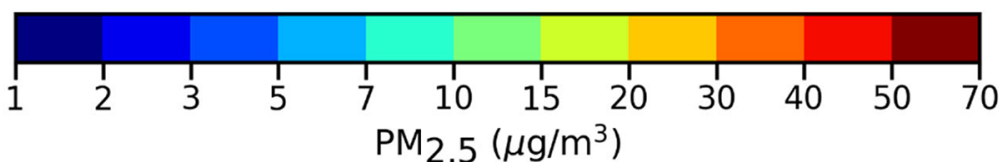

Figure 4. Model-predicted surface $\mathrm{PM}_{2.5}$ concentrations with the four LBCs on 2 July 2015 (the colored circles showing the AIRNow observations). Please note that the dates in this figure are given in the format of month day year (mm/dd/yyyy).

\subsection{The wildfire event in summer 2015}

During the same period of summer 2015, a wildfire event occurred in Canada, and the biomass burning plume was transported to the northern USA, as shown in Fig. 2. While the dust storm intrusions mainly affected the aerosol concentrations, the biomass burning plumes also included gaseous pollutants, such as enhanced levels of $\mathrm{CO}, \mathrm{NO}_{x}$, and VOCs, which could affect the photochemical generation of ozone. For aerosol species, the biomass burning air mass mainly consisted of elemental carbon (EC) and primary organic carbon (POC), which are associated with AECJ+APOCJ in CMAQ (Table 3). GEOS-LBC showed the highest aerosol and $\mathrm{CO}$ concentrations with AECJ + APOCJ up to $300 \mu \mathrm{g} \mathrm{m}^{-3}$ and $\mathrm{CO}$ up to $3000 \mathrm{ppbv}$ along the domains northern boundary (Fig. 7). It also showed $\mathrm{CO}$ enhancement at elevated altitudes up to $12 \mathrm{~km}$ (Fig. 7b). The monthly averaged CLBCs, GLBC-Monthly, had patterns similar to GEOS-LBC but with much lower concentrations (Fig. 7c and d). NGAC-LBC had similar AECJ + APOCJ profiles to those of GLBC-Monthly, but its static CO boundary condition (same as CMAQ_Base) did not reflect the wildfire influence (Fig. 7e and f).
The enhanced gaseous pollutants in the full-chemistry CLBCs increased the photochemical generation of ozone, and consequently the higher ozone appeared along the northcentral boundary (Fig. S1a and b in the Supplement), where GEOS-LBC showed $10 \mathrm{ppbv}$ or higher $\mathrm{O}_{3}$ concentrations compared to the static NGAC-LBC and CMAQ_Base for the altitudes of $<4 \mathrm{~km}$ (Fig. S1c). The wildfire-induced ozone enhancements appeared not only in the lower troposphere but also at higher altitudes, e.g., $11 \mathrm{~km}$, and were not solely due to downward transport of high stratospheric ozone (Fig. S1a). The full-chemistry GEOS-LBC also indicated that the shortlived $\mathrm{NO}_{x}$ had less than a 1 ppbv increase (Fig. S2a) due to the wildfire intrusion. The $\mathrm{NO}_{z}$ (sum total of all $\mathrm{NO}_{x}$ oxidation products, $\mathrm{NO}_{z}=\mathrm{NO}_{y}-\mathrm{NO}_{x}$ ) enhancements, however, could reach $30 \mathrm{ppbv}$ (Fig. S2b) along the northern boundary around $10-12 \mathrm{~km}$ altitude and co-existed with the $\mathrm{CO}$ increments (Fig. 7b). $\mathrm{NO}_{z}$ is a good indicator for the photochemical formation of ozone (Sillman et al., 1997), while the $\mathrm{O}_{3} / \mathrm{NO}_{z}$ ratio represents the ozone photochemical efficiency per $\mathrm{NO}_{x}$. The high-altitude $\mathrm{CO}$ and $\mathrm{NO}_{z}$ increments reflected that the GEOS model had strong fire plume rise and injected wildfire emissions into the upper troposphere. The VOCs also showed increments due to the wildfire, which 
(a) CMAQ Base Predicted $\mathrm{PM}_{2.5}$ at $18 \mathrm{Z}, 07 / 05 / 2015$

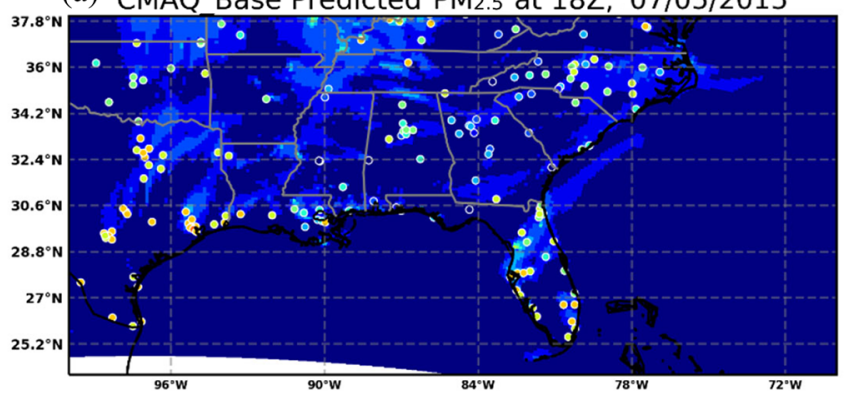

(c) GLBC-Monthly Predicted PM2.5 at 18Z, 07/05/2015

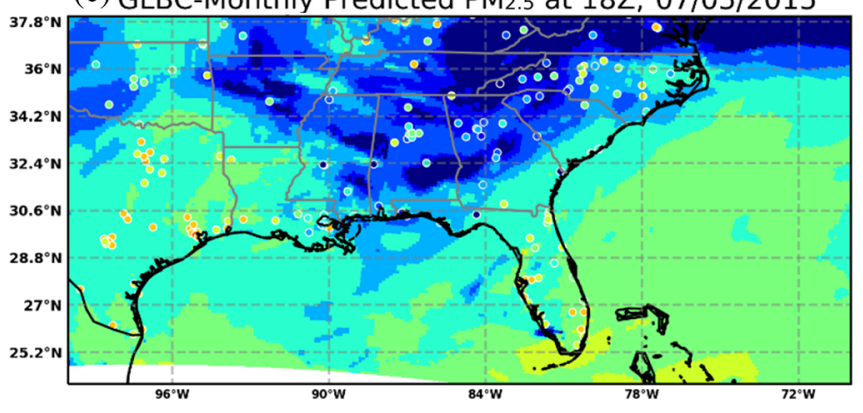

(b) GEOS5-LBC Predicted PM2.5 at 18Z, 07/05/2015

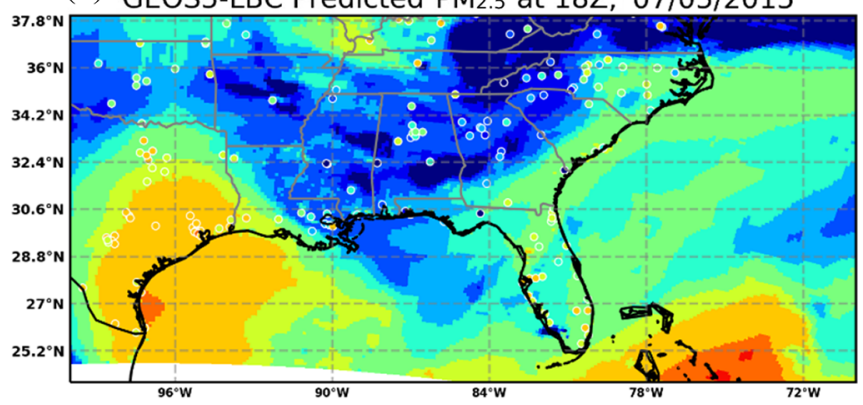

(d) NGAC-LBC Predicted $\mathrm{PM}_{2.5}$ at $18 \mathrm{Z}, 07 / 05 / 2015$

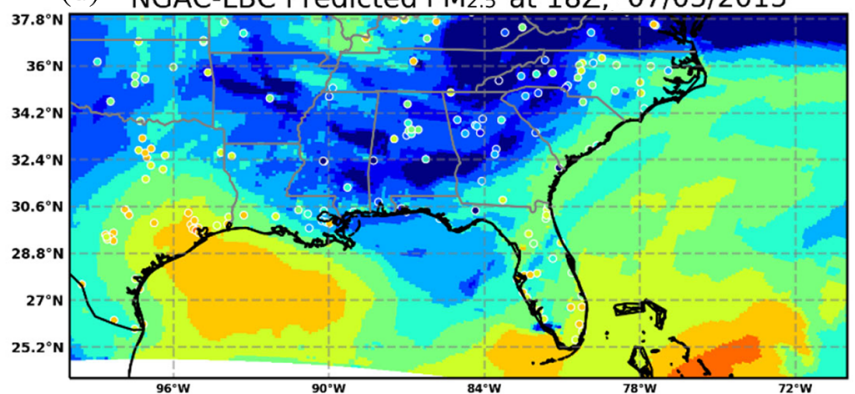

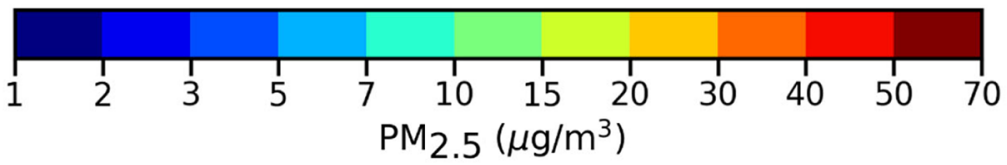

Figure 5. Same as Fig. 4 but for 5 July 2015. Please note that the dates in this figure are given in the format of month day year (mm/dd/yyyy).

mainly provided the VOC- and CO-rich air mass with limited $\mathrm{NO}_{x}$ to the regional CMAQ model. When this CO- and VOC-rich air mass arrived at $\mathrm{NO}_{x}$-rich regions, such as the urban areas, it could contribute to the photochemical generation of ozone.

Figure 8 shows the comparison of $\mathrm{PM}_{2.5}$ predictions on 3 July 2015 at 18:00 UTC. CMAQ_Base missed the intruded biomass burning plumes and the corresponding high $\mathrm{PM}_{2.5}$ over North Dakota, South Dakota, Montana, and Minnesota (Fig. 8a). GEOS-LBC predicted the highest $\mathrm{PM}_{2.5}$ increment (up to $200 \mu \mathrm{g} \mathrm{m}^{-3}$ ) over these states and agreed best with the AIRNow observations (Fig. 8b). The dynamic NGAC-LBC and static GLBC-Monthly showed similar $\mathrm{PM}_{2.5}$ enhancements over the affected states but were almost 1 order of magnitude lower than that of GEOS-LBC.

Figure 9 shows similar predictions but for ozone, where GEOS-LBC yielded the highest ozone increase due to the wildfire plume but still underestimated the ozone over North Dakota (Fig. 9b). GLBC-Monthly systematically underestimated the ozone over all of these regions. CMAQ_Base and NGAC-LBC used the same static gaseous CLBCs, including that for ozone, and gave even larger underestimates. NGAC-
LBC had more wildfire-induced aerosol loading and consequently a lower photolysis rate compared to CMAQ_Base. As both NGAC-LBC and CMAQ_Base had the "cleaner" air mass with low concentrations of ozone precursors over the northern USA, the photolysis reduction due to aerosols mainly led to the reduced ozone photolytic destruction, such as $\mathrm{O}_{3} \rightarrow \mathrm{O}^{1} \mathrm{D}+\mathrm{O}_{2}$ or $\mathrm{O}_{3} \rightarrow \mathrm{O}^{3} \mathrm{P}+\mathrm{O}_{2}$, instead of its photochemical generation. For the same reason, ozone's lifetime in winter is longer that in summer (Janach, 1989). Over polluted regions, however, the photolysis reduction would cause a lower ozone concentration by limiting its photochemical production. Overall, this effect of photolysis rates on ozone was relatively small.

Figure 10 shows the time-series comparison over the north-central and northeastern USA for surface $\mathrm{PM}_{2.5}$ and ozone concentrations, in which GEOS-LBC showed better $\mathrm{PM}_{2.5}$ predictions compared to the other cases, especially from 29 June to 2 July over the northern USA. GEOS-LBC still had the systematic $\mathrm{PM}_{2.5}$ underestimation on the night of 4 July due to the missed firework emissions and underestimated $\mathrm{PM}_{2.5}$ further downwind in the northwestern USA. GEOS-LBC also better captured the peak ozone concen- 
(a)
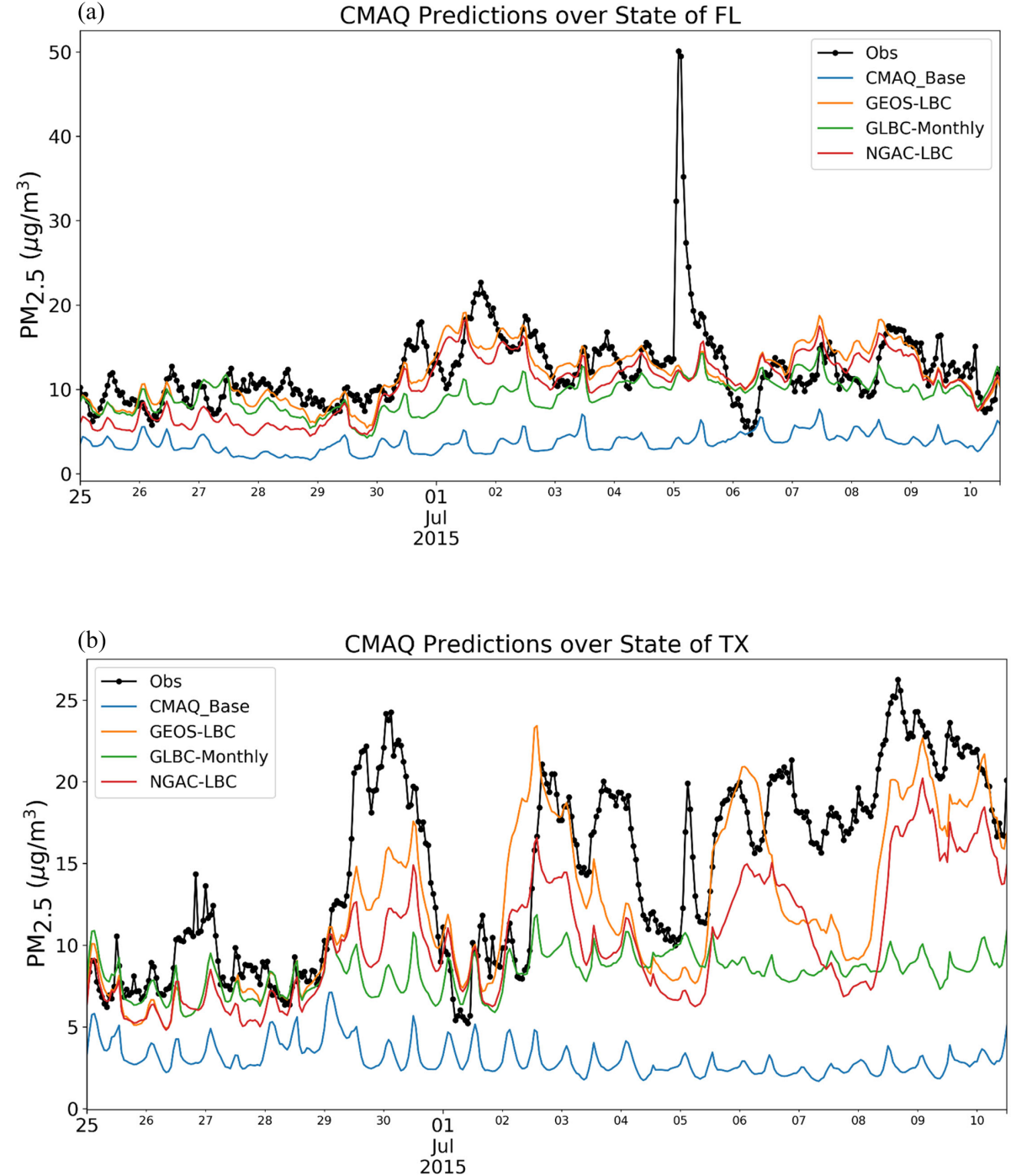

Figure 6. Time-series $\mathrm{PM}_{2.5}$ comparisons over the states of Florida (FL) and Texas (TX). All the times are in UTC.

trations, e.g., 1 to 2 July, though it overpredicted ozone in some instances, especially during nighttime. The small ozone differences (regional averages of $<1 \mathrm{ppbv}$ ) between CMAQ_Base and NGAC-LBC reflected the impact of wildfire aerosols on the photolysis rates (Fig. 9c and d).

\subsection{Statistics and discussion}

Table 4 summarizes the $\mathrm{PM}_{2.5}$ statistics during the 2 weeks of the intrusion events over the CONUS domain and subregions. The dynamic CLBCs, GEOS-LBC and NGACLBC, showed significant improvements for almost all scores over these regions as compared to CMAQ_Base. GLBCMonthly was also better than the base case, though its correlation coefficient $(R)$ and index of agreement (IOA) were lower than those of the dynamics CLBCs, as the timeaveraging method removed the temporal variability. Over the further downwind regions of the intrusion events, the
CLBCs' impact depended on the regional characteristics of the pollutant concentrations. For instance, since the Rocky Mountain region was relatively clean due to its low local $\mathrm{PM}$ emissions, the external influence weighed more, and thus the CLBCs showed more significant impact there. Over more polluted regions where relatively strong local PM emissions existed, such as the Pacific Coast and the northeastern USA, the CLBCs mainly changed the background concentration for $\mathrm{PM}_{2.5}$ and had a very limited impact on $R$ or IOA. Overall, GEOS-LBC yielded the best scores in terms of mean bias (MB), root mean square error (RMSE), $R$, and IOA. The other dynamic CLBCs, NGAC-LBC, had the next best performance, and CMAQ_Base ranked last in terms of the $\mathrm{PM}_{2.5}$ prediction.

Table 5 shows the similar statistics for ozone. CMAQ_Base had a preexisting $\mathrm{O}_{3}$ overprediction, especially over the south-central USA, which affected the 
(a) GEOS AECJ+APOCJ Lateral Boundary Condition at 22Z, 07/02/2015

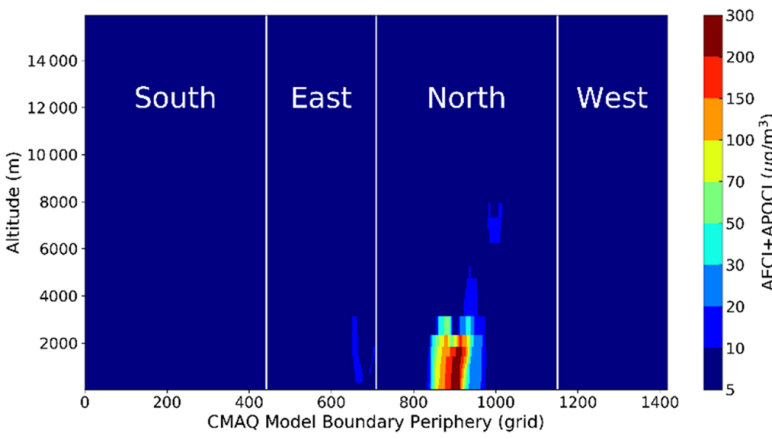

(c) GLBC-Monthly AECJ+APOCJ Lateral Boundary Condition For July, 2015

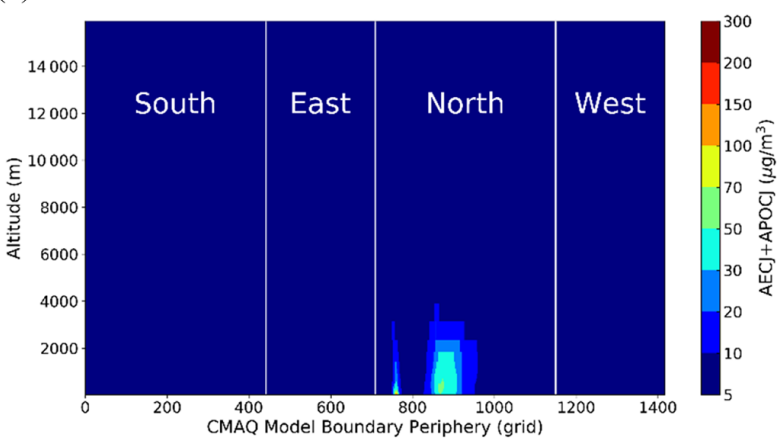

(e) NGAC AECJ+APOCJ Lateral Boundary Condition at 212, 07/02/2015

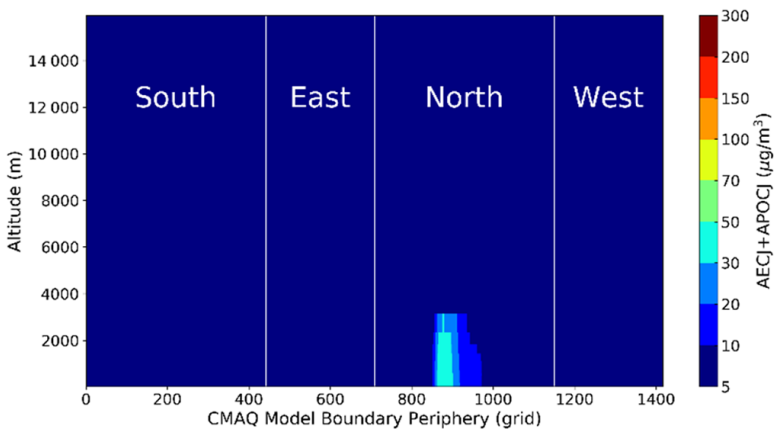

(b) GEOS CO Lateral Boundary Condition at 22Z, 07/02/2015

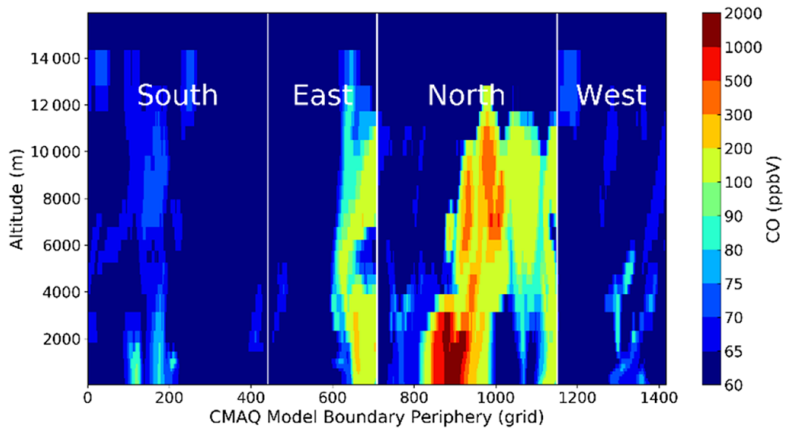

(d) GLBC-Monthly CO Lateral Boundary Condition For July, 2015

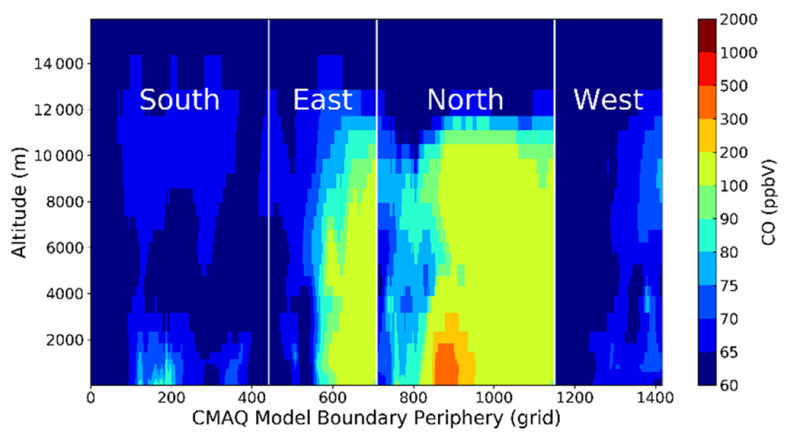

(f) NGAC/CMAQ_Base CO Lateral Boundary Condition For July, 2015

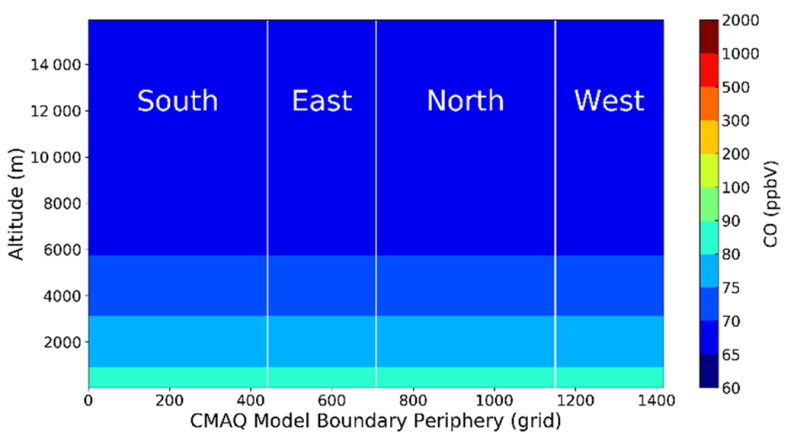

Figure 7. Same as Fig. 3 except for total EC and POC (AECJ + APOCJ) $(\mathbf{a}, \mathbf{c}, \mathbf{e})$ and $\mathrm{CO}(\mathbf{b}, \mathbf{d}, \mathbf{f})$. Please note that the dates in this figure are given in the format of month day year (mm/dd/yyyy).

impacts of the CLBCs and the corresponding model performance changes. Differing from $\mathrm{PM}_{2.5}$, ozone had strong diurnal variation during the summertime, which resulted in relatively fewer impacts of the CLBCs on $R$ and IOA. NGAC-LBC did not change any precursor concentrations related to ozone production and thus only affected the ozone formation by reducing photolysis rates. Therefore, as compared to CMAQ_Base, NGAC-LBC had very weak influence on $\mathrm{O}_{3}$ and only reduced the regional $\mathrm{O}_{3}$ by around $0.2 \mathrm{ppbv}$, with little to no impact on $R$ or IOA. GEOS-LBC tended to increase ozone concentrations in most regions, except the south-central USA, where GEOS-LBC showed general improvement for all statistical metrics. GEOS-LBC had the weakest impact on ozone over the Pacific Coast and
Rocky Mountain regions or the farther downstream areas. GLBC-Monthly had the largest ozone increase over most regions except the south-central region and also had the slightly higher RMSE. This result suggests that averaging the temporal variation of CLBCs may not have a linear effect on ozone predictions. GEOS-LBC showed the best model performance compared to other runs except the mean bias over most regions, though its improvement for $\mathrm{O}_{3}$ was not as significant as that for $\mathrm{PM}_{2.5}$. As discussed above, the CLBCs' impact on ozone inside the domain was realized through changing inflow concentration of the $\mathrm{O}_{3}$ inflow itself and/or $\mathrm{O}_{3}$ precursors, such as $\mathrm{NO}_{x}, \mathrm{VOC}$, or $\mathrm{CO}$. The distance or depth of the CLBCs' effective impact from the inflow boundary depended on the lifetime of these species. 
(a) CMAQ Base Predicted $\mathrm{PM}_{2.5}$ at $18 Z, 07 / 03 / 2015$

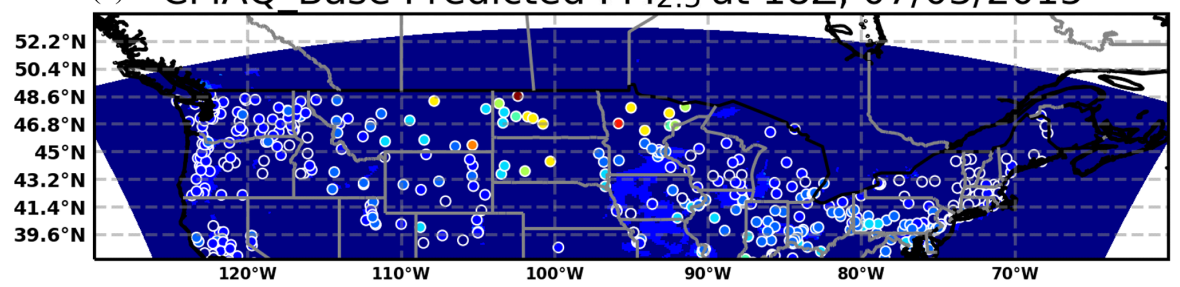

(b) GEOS-LBC Predicted $\mathrm{PM}_{2.5}$ at $18 \mathrm{Z}, 07 / 03 / 2015$

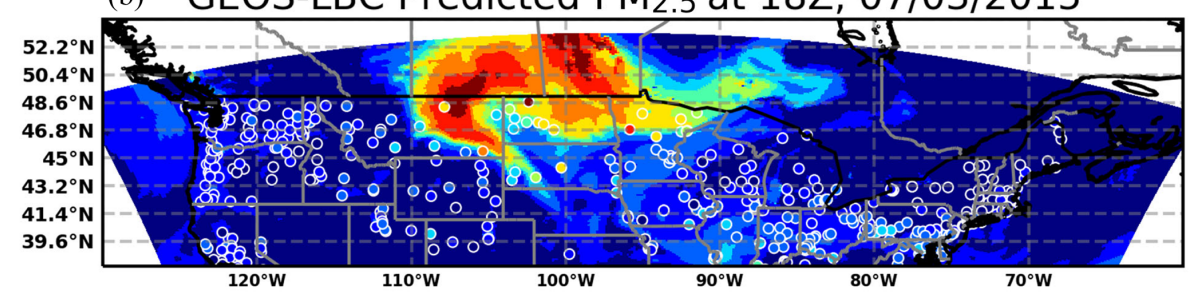

c) (c) GLBC-Monthly Predicted PM2.5 at $18 Z, 07 / 03 / 2015$

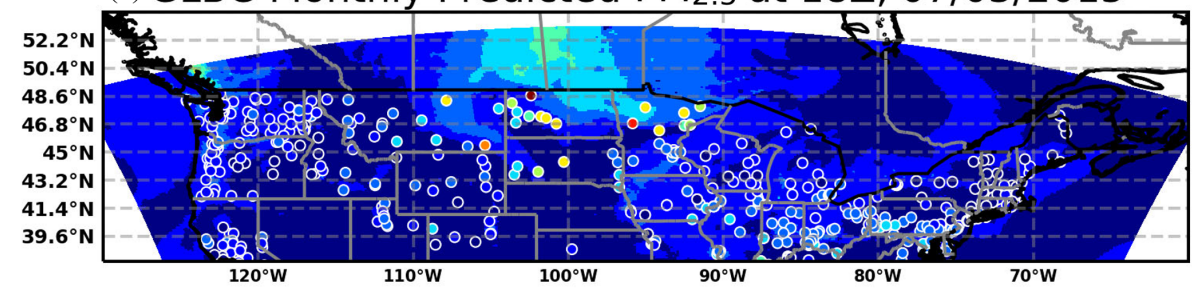

(d) NGAC-LBC Predicted PM2.5 at 18Z, 07/03/2015
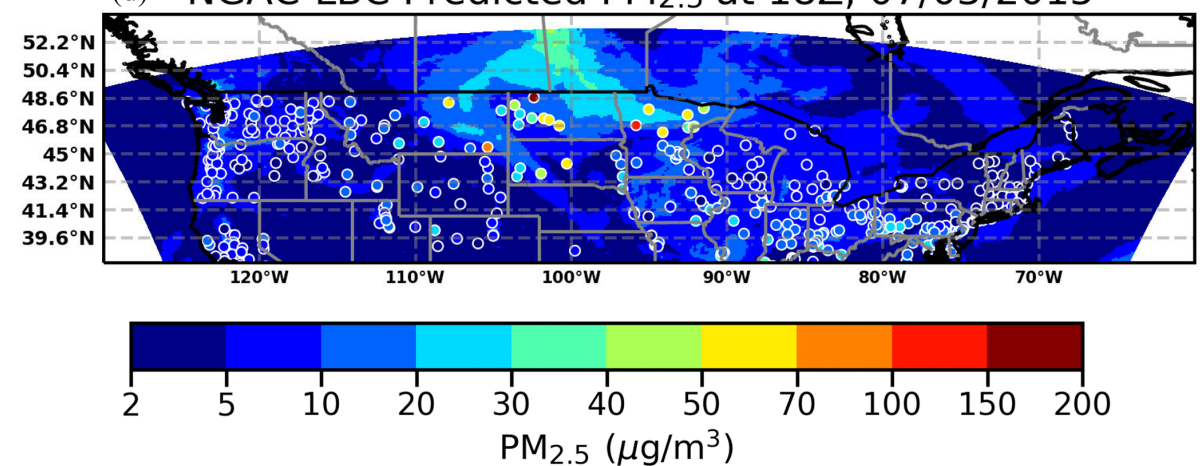

Figure 8. Same as Fig. 4 but for the northern USA on 3 July 2015. Please note that the dates in this figure are given in the format of month day year (mm/dd/yyyy). This figure is plotted using cartopy https://scitools.org.uk/cartopy/docs/latest/ (last access: February 2021), which uses the national and state border information from http://www.naturalearthdata.com/ (last access: February 2021). Please note that the above figure contains incomplete US state borders.

All these species have a longer lifetime in winter compared to summer. Our other study showed that the CLBCs' impact on ozone in winter was stronger than that in summer.

The GEOS-LBC case is further used to illustrates the impact of CLBCs on the prediction statistics and their relations to the distance from the domain boundary during the pollutant intrusion events across the southern (the Saharan dust storm, Fig. 11a and b) and the northern USA (wildfire, Fig. 11c and d). The CLBCs have two effects for the regional predictions: (1) they provide a constraint for background concentrations represented by the mean biases, and (2) they introduce a dynamic external influence, represented by the correlation coefficients. The CLBC impacts on the background and variability both affect the RMSE of predictions. Over the southern USA, the Saharan dust storm intruded through the states of Texas and Louisiana, 100 to $86^{\circ} \mathrm{W}$, and moved northward (Fig. 4). Figure 11a showed that GEOSLBC's improvement on the correlation coefficient $(R)$ for the $\mathrm{PM}_{2.5}$ prediction reached the highest near the southernmost near-boundary region and gradually reduced along the latitude for the inland region. On the other hand, the corresponding $\mathrm{MB}$ improvement for $\mathrm{PM}_{2.5}$ did not show a significant reduction along the distance from the influenced boundary. The second effect of CLBCs, which constrains $\mathrm{PM}_{2.5}$ back- 
(a) CMAQ Base Predicted $\mathrm{O}_{3}$ at $18 \mathrm{Z}, 07 / 02 / 2015$

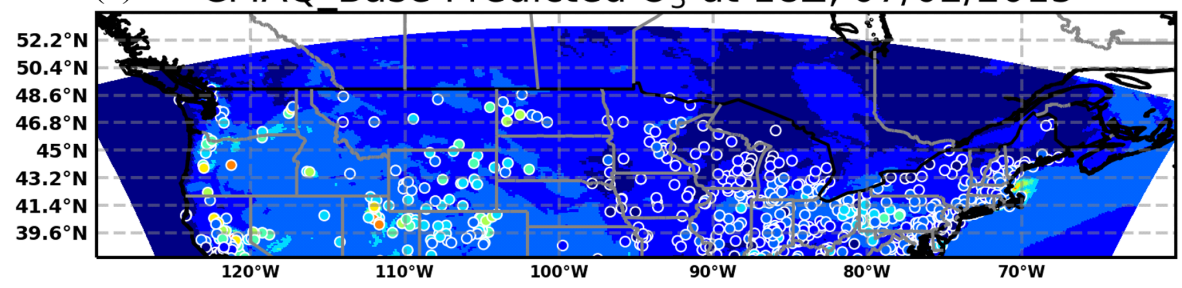

(b) GEOS-LBC Predicted $\mathrm{O}_{3}$ at $18 \mathrm{Z}, 07 / 03 / 2015$

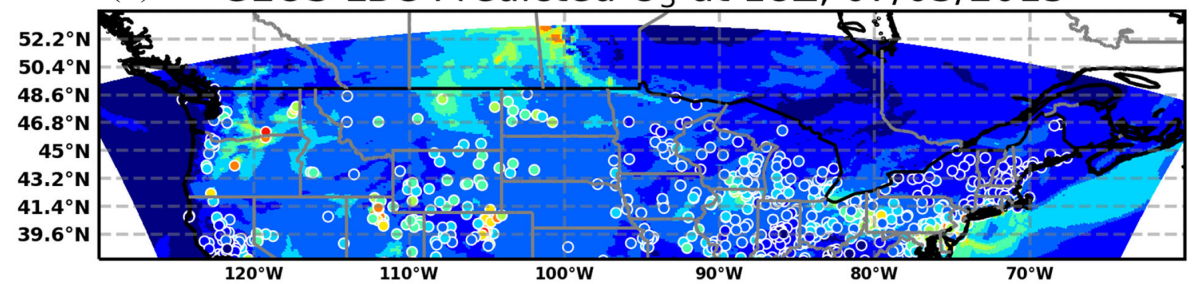

(c) GLBC-Monthly Predicted $\mathrm{O}_{3}$ at $18 \mathrm{Z}, 07 / 03 / 2015$

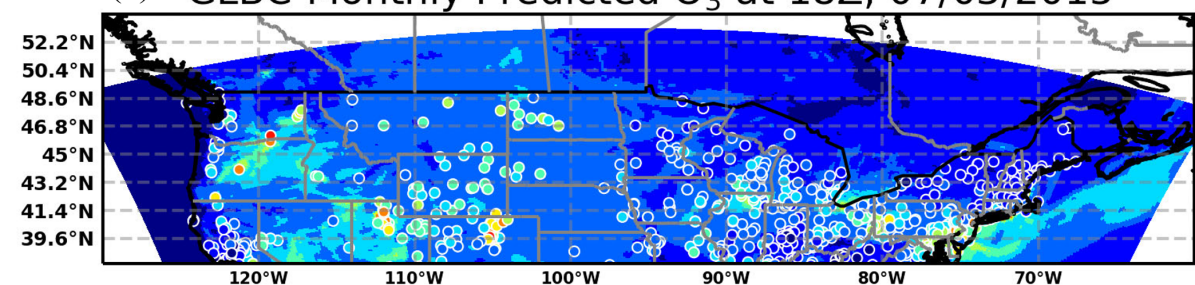

(d) NGAC-LBC Predicted $\mathrm{O}_{3}$ at $18 \mathrm{Z}, 07 / 03 / 2015$
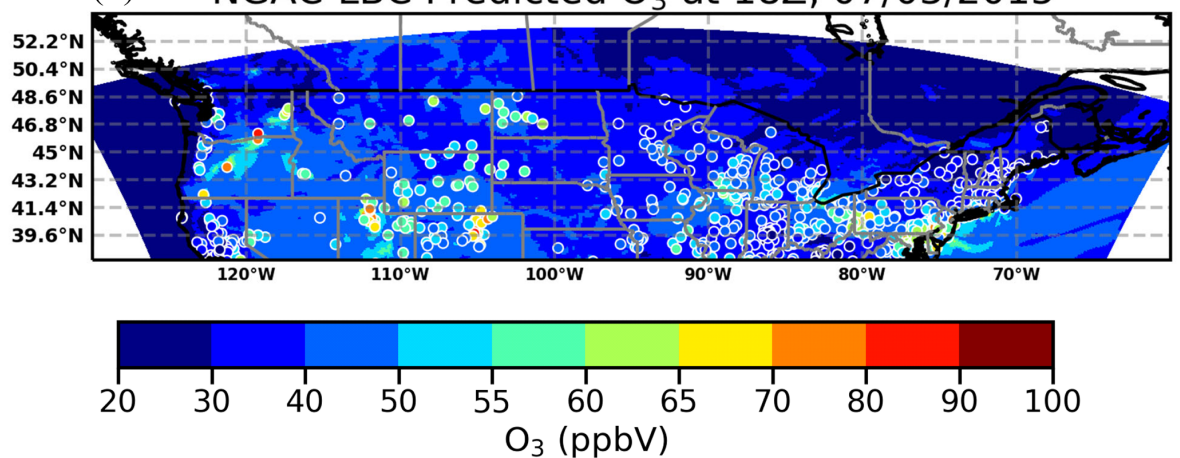

Figure 9. Same as Fig. 8 but for $\mathrm{O}_{3}$. Please note that the dates in this figure are given in the format of month day year (mm/dd/yyyy). This figure is plotted using cartopy https://scitools.org.uk/cartopy/docs/latest/ (last access: February 2021), which uses the national and state border information from http://www.naturalearthdata.com/ (last access: February 2021). Please note that the above figure contains incomplete US state borders.

ground concentrations, can exist further inside of the domain. The $\mathrm{PM}_{2.5}$ RMSE change reflected the combined changes of the MB and $R$ value. The improving impact of GEOSLBC on the RMSE also became weaker moving from the boundary because the MB did not vary much and the RMSE changes followed the correlation coefficient's change northward. Contrary to $\mathrm{PM}_{2.5}$, the most significant $R$ improvement for $\mathrm{O}_{3}$ was not near the boundary but rather for more northward regions $\left(29\right.$ to $\left.32^{\circ} \mathrm{N}\right)$ (Fig. 11b). Overall, for the dynamic CLBCs, the improvements in the ozone $\mathrm{MB}$ and RMSE have similar spatial variability, which is more significant near the inflow boundary and fades further inland.
Differences in $\mathrm{PM}_{2.5}$ and $\mathrm{O}_{3}$ statistics arise because $\mathrm{O}_{3}$ typically has a stronger diurnal variation in summer driven by local photochemical activities in polluted regions, which may impact the correlation more than the external CLBCs. Therefore, GEOS-LBC's major influence on $\mathrm{O}_{3}$ prediction for this event was changing the $\mathrm{O}_{3}$ background concentration. The GEOS-LBC MB change for ozone was also variable compared to the CMAQ_Base case northward from the boundary (Fig. 11b). GEOS-LBC had a lower ozone concentration compared to CMAQ_Base at low altitudes for the southern boundary but had higher ozone concentrations in the altitudes higher than $14 \mathrm{~km}$ (Fig. S1). The high ozone 
(a)

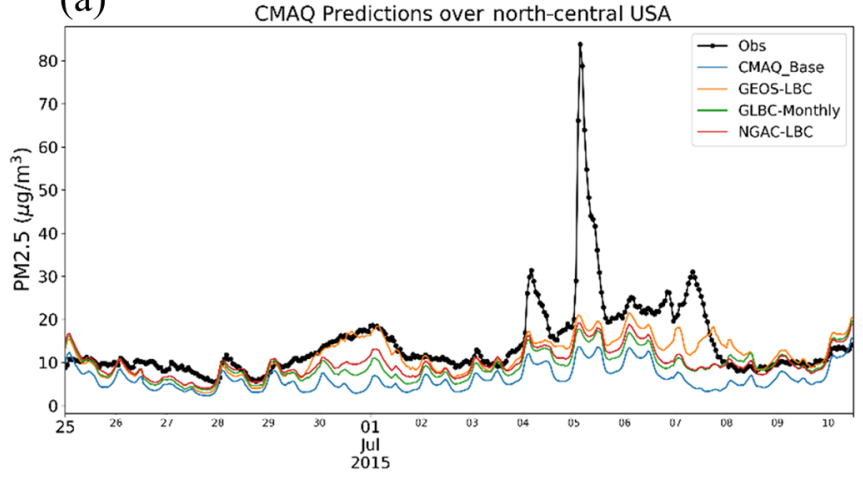

(c)

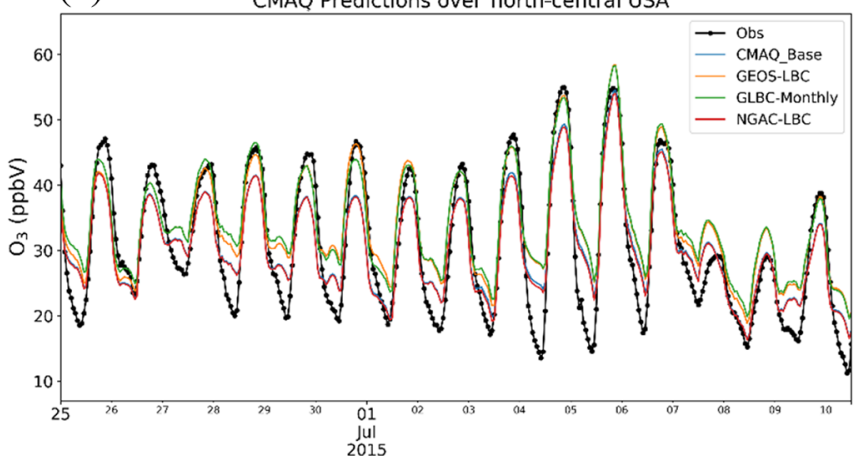

(b)

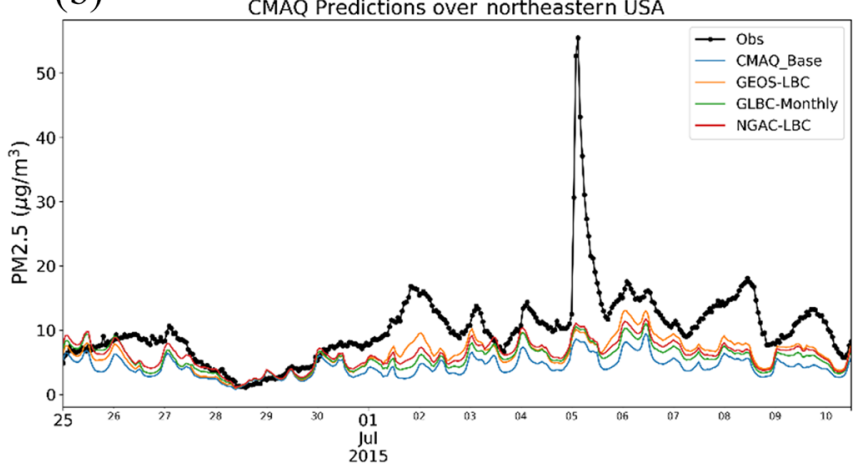

(d)

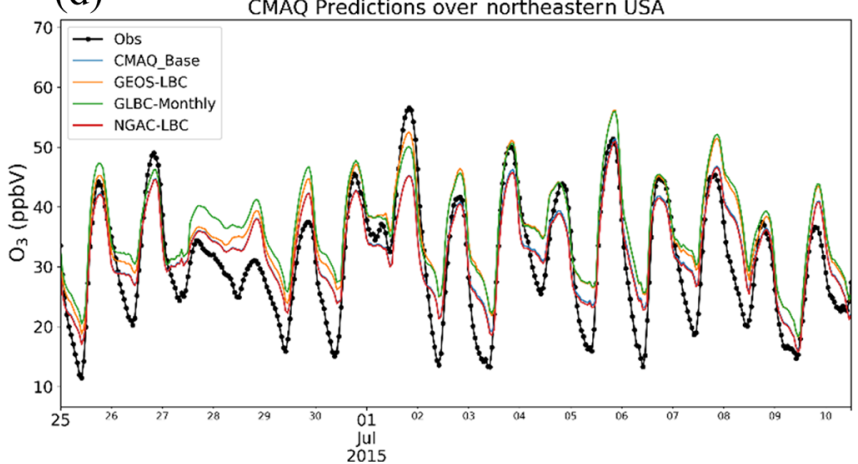

Figure 10. Time-series comparisons for $\mathrm{PM}_{2.5}(\mathbf{a}, \mathbf{b})$ and $\mathrm{O}_{3}(\mathbf{c}, \mathbf{d})$ over the north-central region (a, c) (states of Illinois, Indiana, Iowa, Kentucky, Michigan, Minnesota, Missouri, Ohio, and Wisconsin) and northeastern USA (b, d) (states of Connecticut, Delaware, Maine, Maryland, Massachusetts, New Hampshire, New Jersey, New York, Pennsylvania, Rhode Island and Vermont and the District of Columbia).

concentration could reach the surface after a certain distance of downward transport in the model system with strong vertical mixing (Tang et al., 2009), which results in the higher ozone MB of GEOS-LBC over the deeper inland region.

There was a similar spatial distribution for the $\mathrm{PM}_{2.5}$ statistical differences between GEOS-LBC3 and CMAQ_Base for the wildfire intrusion event over the northern USA. The most significant $R$ and RMSE improvements for GEOS-LBC appeared near the boundary, and these improvements were reduced farther from the boundary. However, the corresponding $\mathrm{MB}$ differences could exist deeper inland. For $\mathrm{O}_{3}$, the difference between the GEOS-LBC and CMAQ_Base cases became more complex because wildfire plumes also contained the intrusion from $\mathrm{O}_{3}$ and its precursors. The GEOS-LBC run generally yielded higher $\mathrm{O}_{3}$, which exacerbated the preexisting model overprediction near the boundary but helped reduce the ozone underpredictions further inland (Fig. 11d). The largest $\mathrm{O}_{3} \mathrm{MB}$ differences were also farther away from the boundary itself, as it took more time for the for ozone precursors to contribute to the photochemical formation of $\mathrm{O}_{3}$. The spatial variation of the $\mathrm{O}_{3}$ RMSE difference was similar to that of the $\mathrm{O}_{3} \mathrm{MB}$ except for the further inland region, such as south of $43^{\circ} \mathrm{N}$, where GEOS-LBC did not improve the RMSE. A similar issue also appeared for the $R$ difference for the region south of $46^{\circ} \mathrm{N}$, implying that the intruded wild- fire plume represented by GEOS-LBC could introduce some spatial or temporal biases for $\mathrm{O}_{3}$ precursors.

\section{AOT-derived lateral boundary conditions}

The dynamic CLBCs, such as GEOS-LBC, showed an overall better prediction of the pollutant intrusion events by better capturing the spatiotemporal impacts of external gases and aerosols across the domain of the regional model. However, the full-chemistry CLBCs sometimes are not easy to obtain, especially for a near-real-time forecast. Some eventdependent emissions, including wildfires, may need additional time to retrieve and refine and thus may lag behind the valid forecast times. In order to represent the intrusion influence when the real-time model CLBCs are not available, we test an alternative CLBC method based on the historical data adjusted with certain indicators. Here we focus on the wildfire intrusion, since it is more difficult to capture the sudden outbreak of wildfire signals than the long-range transporteddust intrusion. Further alleviating this issue for dust intrusion is the current availability of the operational NGAC dust forecasting for NAQFC (Wang et al., 2018). 
Table 4. Regional $\mathrm{PM}_{2.5}$ statistics of the four simulations (CMAQ_Base, GEOS-LBC, GLBC-Monthly, and NGAC-LBC) from 24 June to 8 July 2015.

\begin{tabular}{|c|c|c|c|c|c|}
\hline Regions & Simulations & $\begin{array}{c}\text { Mean } \\
\text { bias } \\
\left(\mu \mathrm{g} \mathrm{m}^{-3}\right)\end{array}$ & $\begin{array}{r}\text { Root } \\
\text { mean } \\
\text { square } \\
\text { error } \\
\left(\mu \mathrm{g} \mathrm{m}^{-3}\right)\end{array}$ & $\begin{array}{c}\text { Correlation } \\
\text { coefficient } \\
R\end{array}$ & $\begin{array}{c}\text { Index of } \\
\text { agreement }\end{array}$ \\
\hline \multirow{4}{*}{$\begin{array}{l}\text { Contiguous } \\
\text { USA }\end{array}$} & CMAQ_Base & -6.74 & 13.69 & 0.18 & 0.37 \\
\hline & GEOS-LBC & -2.96 & 12.16 & 0.37 & 0.55 \\
\hline & GLBC-Monthly & -4.10 & 12.39 & 0.27 & 0.41 \\
\hline & NGAC-LBC & -3.30 & 12.09 & 0.30 & 0.44 \\
\hline \multirow{4}{*}{$\begin{array}{l}\text { Northeastern } \\
\text { USA }\end{array}$} & CMAQ_Base & -5.52 & 10.93 & 0.33 & 0.43 \\
\hline & GEOS-LBC & -3.81 & 9.89 & 0.40 & 0.50 \\
\hline & GLBC-Monthly & -4.25 & 10.31 & 0.34 & 0.45 \\
\hline & NGAC-LBC & -3.70 & 10.05 & 0.35 & 0.46 \\
\hline \multirow[t]{4}{*}{ Pacific Coast } & CMAQ_Base & -3.96 & 10.63 & 0.16 & 0.31 \\
\hline & GEOS-LBC & -2.02 & 10.22 & 0.18 & 0.34 \\
\hline & GLBC-Monthly & -1.53 & 10.21 & 0.17 & 0.34 \\
\hline & NGAC-LBC & -0.79 & 10.33 & 0.16 & 0.34 \\
\hline \multirow{4}{*}{$\begin{array}{l}\text { Southeastern } \\
\text { USA }\end{array}$} & CMAQ_Base & -8.18 & 11.35 & 0.14 & 0.44 \\
\hline & GEOS-LBC & -3.07 & 8.39 & 0.37 & 0.58 \\
\hline & GLBC-Monthly & -4.78 & 9.08 & 0.27 & 0.49 \\
\hline & NGAC-LBC & -3.83 & 8.58 & 0.35 & 0.56 \\
\hline \multirow{4}{*}{$\begin{array}{l}\text { Rocky } \\
\text { Mountain } \\
\text { states }\end{array}$} & CMAQ_Base & -7.62 & 17.57 & 0.02 & 0.31 \\
\hline & GEOS-LBC & -3.66 & 15.98 & 0.39 & 0.58 \\
\hline & GLBC-Monthly & -5.42 & 16.06 & 0.23 & 0.36 \\
\hline & NGAC-LBC & -4.65 & 15.78 & 0.24 & 0.36 \\
\hline \multirow{4}{*}{$\begin{array}{l}\text { North- } \\
\text { central } \\
\text { USA }\end{array}$} & CMAQ_Base & -8.32 & 17.63 & 0.25 & 0.38 \\
\hline & GEOS-LBC & -2.95 & 16.47 & 0.33 & 0.52 \\
\hline & GLBC-Monthly & -5.25 & 16.41 & 0.27 & 0.40 \\
\hline & NGAC-LBC & -4.48 & 15.98 & 0.31 & 0.43 \\
\hline \multirow{4}{*}{$\begin{array}{l}\text { South- } \\
\text { central } \\
\text { USA }\end{array}$} & CMAQ_Base & -9.65 & 13.12 & 0.07 & 0.42 \\
\hline & GEOS-LBC & -2.00 & 7.79 & 0.51 & 0.69 \\
\hline & GLBC-Monthly & -4.73 & 9.45 & 0.24 & 0.48 \\
\hline & NGAC-LBC & -3.52 & 8.31 & 0.46 & 0.63 \\
\hline
\end{tabular}

\subsection{Development of the CLBCs with VIIRS AOT for wildfire plumes}

While ground-based AIRNow surface stations are reliable and could be a historical data indicator to represent intrusion events, their spatial coverage along the wildfire intrusion boundaries is not dense enough for this purpose. VIIRS AOT retrievals, however, well reflected the wildfire intrusion with broad spatial coverage, superior to the sporadic surface stations along the northern boundary of the CONUS domain (Fig. 2). Thus, VIIRS AOT may be used as an indicator for wildfire plumes. Figure $\mathrm{S} 3$ showed the comparison of extracted VIIRS AOT versus GEOS CO and EC column loading along the northern boundary for June to July 2015, with their correlation coefficients $(R)$ of $>0.5$. The regression relationship derived out of Fig. S3 can be used to re- sample the historical GEOS-LBC data to derive the new CLBCs for wildfire intrusion events when the corresponding AOT is available. This regression methodology is strengthened by the fact that the domain's northern boundary was relatively clean in most periods of the summer, unless the wildfire events occurred. During June and July 2015, the VIIRS AOT data were available once or twice per day around local noontime under cloud-free conditions. To maximize the amount of VIIRS AOT data used along the northern boundary, we relaxed the radius of influence up to $300 \mathrm{~km}$ when "nearest-neighbor" pairing of the VIIRS AOT geolocation and the northern boundary location. Here we paired the GEOS's northern CLBCs (NLBC) for 18:00 UTC with the daily VIIRS AOT along the same location and averaged the whole column with an AOT interval of 0.2 to build a 
Table 5. Same as Table 4 but for ozone.

\begin{tabular}{|c|c|c|c|c|c|}
\hline Regions & Simulations & $\begin{array}{r}\text { Mean } \\
\text { bias } \\
\text { (ppbv) }\end{array}$ & $\begin{array}{l}\text { Root } \\
\text { mean } \\
\text { square } \\
\text { error } \\
\text { (ppbv) }\end{array}$ & $\begin{array}{c}\text { Correlation } \\
\text { coefficient } \\
R\end{array}$ & $\begin{array}{l}\text { Index of } \\
\text { agreement }\end{array}$ \\
\hline \multirow{4}{*}{$\begin{array}{l}\text { Contiguous } \\
\text { USA }\end{array}$} & CMAQ_Base & 2.10 & 12.35 & 0.64 & 0.77 \\
\hline & GEOS-LBC & 3.47 & 12.01 & 0.68 & 0.79 \\
\hline & GLBC-Monthly & 4.84 & 12.52 & 0.68 & 0.78 \\
\hline & NGAC-LBC & 1.88 & 12.29 & 0.64 & 0.77 \\
\hline \multirow{4}{*}{$\begin{array}{l}\text { Northeastern } \\
\text { USA }\end{array}$} & CMAQ_Base & 1.87 & 10.68 & 0.66 & 0.78 \\
\hline & GEOS-LBC & 4.88 & 11.54 & 0.68 & 0.78 \\
\hline & GLBC-Monthly & 5.60 & 12.02 & 0.66 & 0.76 \\
\hline & NGAC-LBC & 1.62 & 10.64 & 0.66 & 0.78 \\
\hline \multirow[t]{4}{*}{ Pacific Coast } & CMAQ_Base & -2.58 & 12.04 & 0.78 & 0.86 \\
\hline & GEOS-LBC & -2.16 & 11.83 & 0.79 & 0.87 \\
\hline & GLBC-Monthly & 0.46 & 11.79 & 0.78 & 0.87 \\
\hline & NGAC-LBC & -2.76 & 12.08 & 0.78 & 0.86 \\
\hline \multirow{4}{*}{$\begin{array}{l}\text { Southeastern } \\
\text { USA }\end{array}$} & CMAQ_Base & 7.26 & 13.66 & 0.59 & 0.68 \\
\hline & GEOS-LBC & 7.94 & 13.34 & 0.66 & 0.72 \\
\hline & GLBC-Monthly & 9.06 & 14.20 & 0.65 & 0.70 \\
\hline & NGAC-LBC & 7.04 & 13.50 & 0.60 & 0.69 \\
\hline \multirow{4}{*}{$\begin{array}{l}\text { Rocky } \\
\text { Mountain } \\
\text { states }\end{array}$} & CMAQ_Base & -1.91 & 10.61 & 0.67 & 0.80 \\
\hline & GEOS-LBC & -0.17 & 10.45 & 0.67 & 0.80 \\
\hline & GLBC-Monthly & 1.68 & 10.75 & 0.66 & 0.79 \\
\hline & NGAC-LBC & -2.08 & 10.63 & 0.67 & 0.80 \\
\hline \multirow{4}{*}{$\begin{array}{l}\text { North- } \\
\text { central } \\
\text { USA }\end{array}$} & CMAQ_Base & -0.47 & 10.78 & 0.65 & 0.78 \\
\hline & GEOS-LBC & 2.55 & 11.01 & 0.66 & 0.79 \\
\hline & GLBC-Monthly & 3.00 & 11.22 & 0.65 & 0.78 \\
\hline & NGAC-LBC & -0.75 & 10.76 & 0.65 & 0.78 \\
\hline \multirow{4}{*}{$\begin{array}{l}\text { South- } \\
\text { central } \\
\text { USA }\end{array}$} & CMAQ_Base & 13.36 & 17.76 & 0.51 & 0.58 \\
\hline & GEOS-LBC & 10.90 & 14.71 & 0.68 & 0.68 \\
\hline & GLBC-Monthly & 12.66 & 16.24 & 0.66 & 0.64 \\
\hline & NGAC-LBC & 13.12 & 17.56 & 0.51 & 0.58 \\
\hline
\end{tabular}

CLBC database sorted in AOT. We only chose to resample the CLBCs for the primarily emitted species from the wildfire sources, which include POC, $\mathrm{EC}, \mathrm{CO}, \mathrm{NO}_{x}$, and two $\mathrm{NO}_{z}$ species, PAN and $\mathrm{HNO}_{3}$, but did not include the ozone CLBCs. When VIIRS AOT data are available for a NLBC grid in new intrusion events, the whole-column species concentration data from that database are chosen to form the new CLBCs for that grid based on the nearest-neighbor VIIRS AOT value.

\subsection{A case study with VIIRS-AOT-derived LBC in August 2018}

In mid to late August 2018, there were dominant highpressure and dry-weather conditions that led to a wildfire outbreak that quickly spread across western Canada (Fig. S4). There was prevailing north-to-northeast winds, which brought the fire pollutants southward and affected the north-northwestern USA. The corresponding VIIRS AOT retrievals for this event showed high AOT values in western Canada as well as the northern and northwestern USA (Fig. 12a). We used this AOT data to derive new CLBCs along the northern boundary (Fig. 12b and c) for $\mathrm{CO}$ and wildfire-emitted aerosols (AECJ + APOCJ) by resampling the historical GEOS-LBC database from the June-July 2015 period. These AOT-derived northern CLBCs (AOT-NLBC) were updated once per day due to the VIIRS data availability, while the western, southern, and eastern boundaries came from the climatological monthly mean GEOS-LBC (averaged from 2011 to 2015). The AECJ+APOCJ increments of AOT-NLBC mainly existed below $3 \mathrm{~km}$, but the $\mathrm{CO}$ enhancement could reach up to the altitude of $10 \mathrm{~km}$, due to the elevated $\mathrm{CO}$ plume in the original GEOS-LBC, e.g., Fig. 7b. NGAC-LBC (Fig. 13d) also showed the enhanced 
(a) $\mathrm{PM}_{2.5}$ Statistic between $-100^{\circ} \mathrm{W}$ to $-86^{\circ} \mathrm{W}(06 / 24 / 2015-07 / 08 / 2015)$

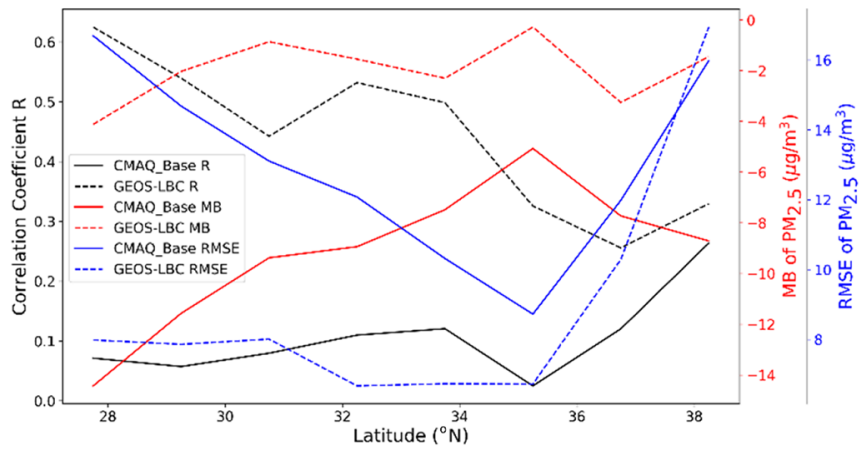

(c) $\mathrm{PM}_{2.5}$ Statistic between $-125^{\circ} \mathrm{W}$ to $-90^{\circ} \mathrm{W}(06 / 24 / 2015-07 / 08 / 2015)$

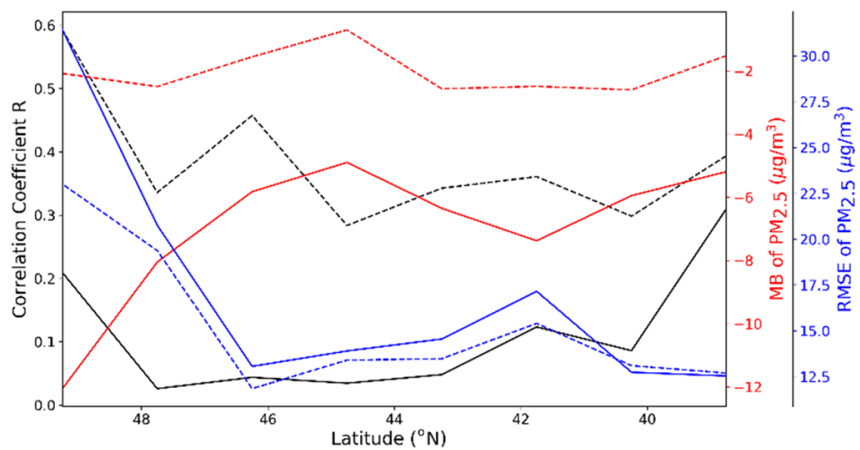

(b) $\mathrm{O}_{3}$ Statistic between $-100^{\circ} \mathrm{W}$ to $-86^{\circ} \mathrm{W}(06 / 24 / 2015-07 / 08 / 2015)$

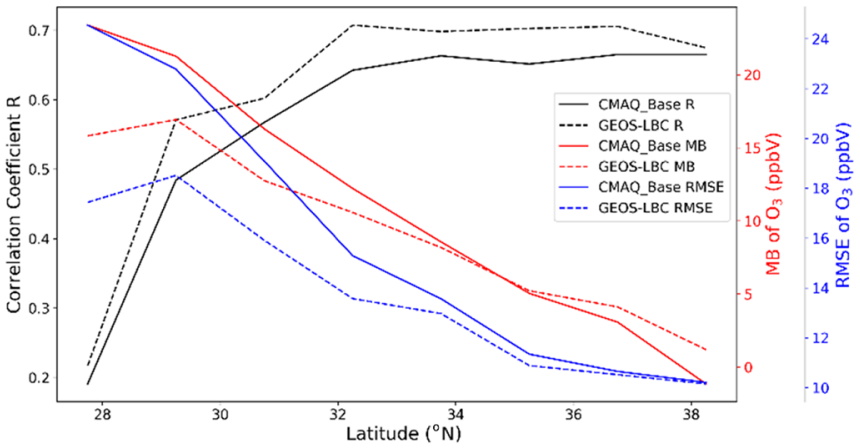

(d) $\mathrm{O}_{3}$ Statistic between $-125^{\circ} \mathrm{W}$ to $-90^{\circ} \mathrm{W}(06 / 24 / 2015-07 / 08 / 2015)$

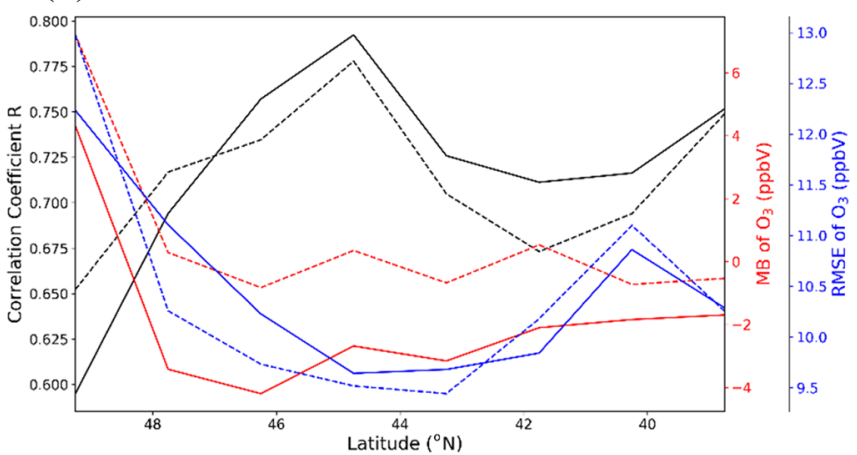

Figure 11. The latitudinal distributions of correlation coefficient $R$ (black), mean bias (MB) (red), and root mean square error (RMSE) (blue) of $\mathrm{PM}_{2.5}(\mathbf{a}, \mathbf{c})$ and $\mathrm{O}_{3}(\mathbf{b}, \mathbf{d})$ concentrations from 24 June to 8 July 2015 over the southern USA (a, b) and northern USA (c, d) for CMAQ_Base (solid line) and GEOS-LBC (dash line) runs. Please note that the dates in this figure are given in the format of month day year $(\mathrm{mm} / \mathrm{dd} / \mathrm{yyyy})$.

AECJ + APOCJ concentrations along the northern boundary, but it was much lower than that of AOT-NLBC. In addition, unlike AOT-NLBC's two peaks, NGAC-LBC mainly just showed one peak near the northwestern boundary.

Figure 13 shows the surface ozone and $\mathrm{PM}_{2.5}$ concentrations over this region $1 \mathrm{~d}$ later (17 August 2018). CMAQ_Base underpredicted both species over this region, and AOT-NLBC reduced the underprediction by increasing background concentrations from the northern boundary. Since AOT-NLBC did not include the dynamic ozone boundary conditions, any enhancements in ozone concentration were due to the $\mathrm{CO}$ and $\mathrm{NO}_{x}$ enhancements transported from the northern boundary, which sometimes caused the overprediction over further downwind areas, such as North Dakota. Overall, AOT-NLBC showed better $\mathrm{PM}_{2.5}$ prediction over southwestern Canada and the northwestern USA due to the higher background concentrations. NGAC-LBC had nearly the same ozone concentration as CMAQ_Base (Fig. 13e) and also had the similar $\mathrm{PM}_{2.5}$ background enhancements to that of AOT-NLBC over the northwestern USA. Unlike AOTNLBC, NGAC-LBC did not show the $\mathrm{PM}_{2.5}$ increases east of $96^{\circ} \mathrm{W}$ compared to the CMAQ_Base run, as AOT-NLBC had additional aerosol increment peaks over the north-central boundary. However, that aerosol background enhancement of AOT-NLBC led to the $\mathrm{PM}_{2.5}$ overprediction over Minnesota, implying that the derived CLBCs could incur some errors.

Figure 14 shows the corresponding models versus AIRNow time-series comparisons over EPA region 8 (states of Montana, North Dakota, South Dakota, Wyoming, Colorado, and Utah), region 10 (states of Washington, Idaho, and Oregon), region 5 (states of Minnesota, Wisconsin, Illinois, Indiana, Michigan, and Ohio), and region 9 (states of California, Nevada, and Arizona). Both observed and predicted ozone showed strong diurnal variation. AOTNLBC showed better skill in capturing daytime ozone maximum for regions 8 and 10 with about 3-10 ppbv higher amounts than the CMAQ_Base prediction, though it tended to overpredict ozone at night. Over EPA region 5 (northcentral USA), the ozone differences between the AOT-NLBC and CMAQ_Base runs became narrower, since the major pollutant intrusion from this event occurred in the northwestern USA. AOT-NLBC increased the preexisting high bias for ozone over region 5. Region 9 (southwestern USA) was located further downwind from the domain's northern boundary, meaning it should get a much weaker influence from AOT-NLBC. However, during the period of 21-25 Au- 

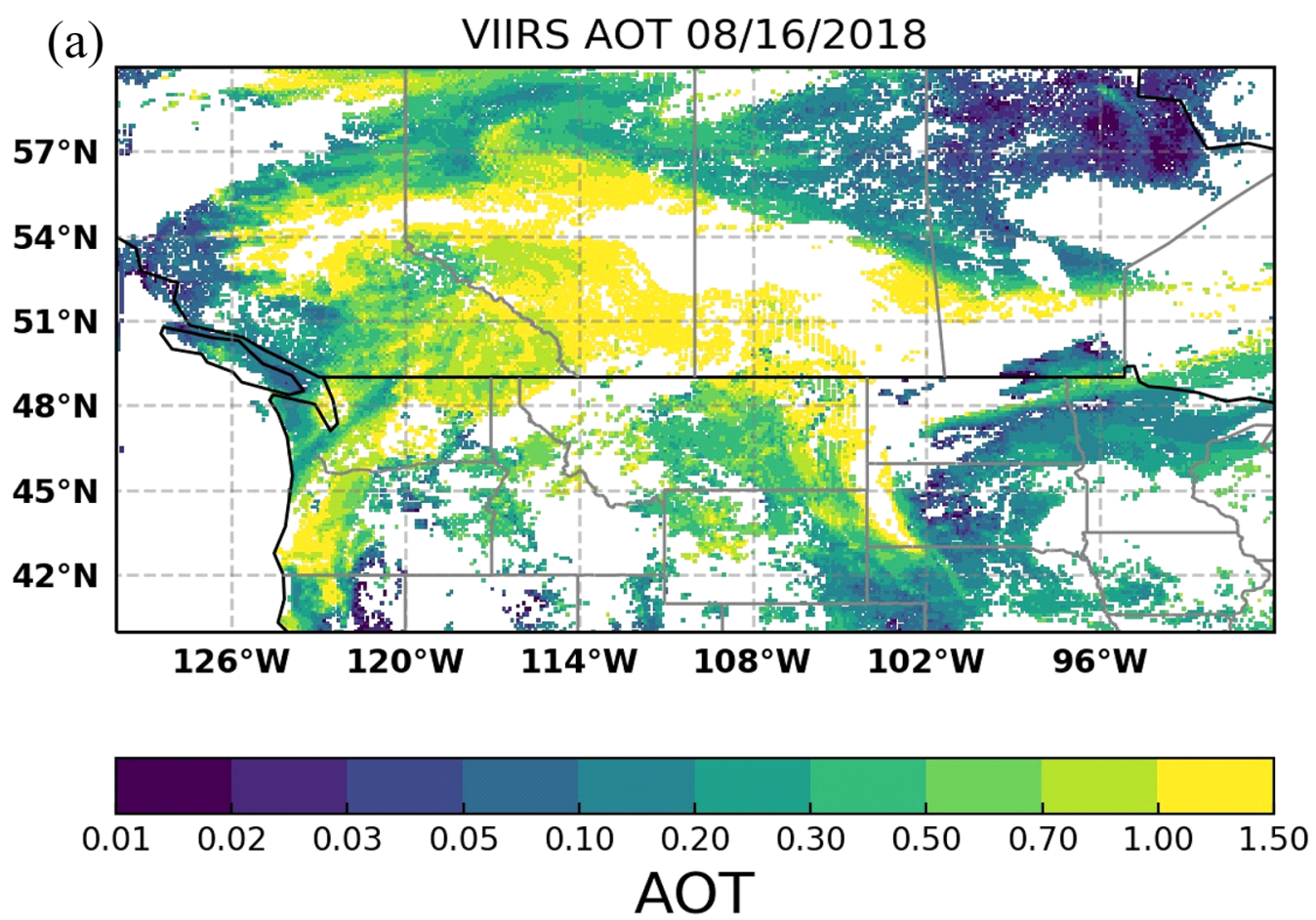

(b) AOT-NLBC CO Lateral Boundary Condition at 18Z, 08/16/2018

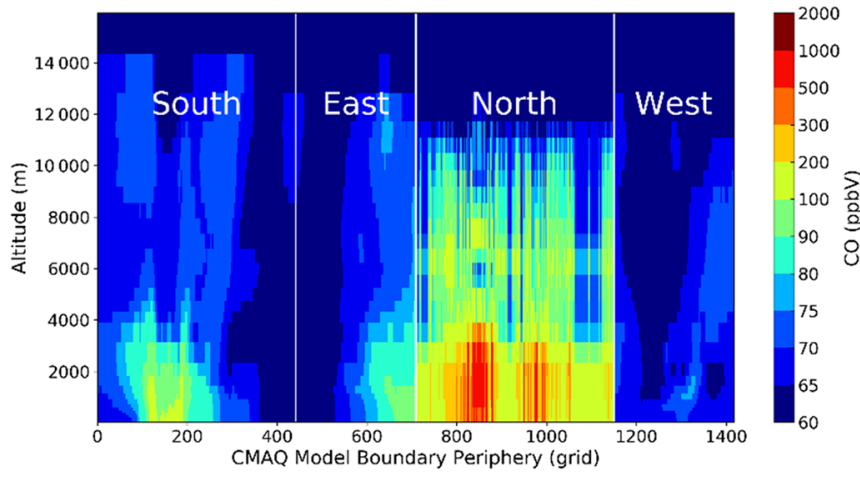

(c)

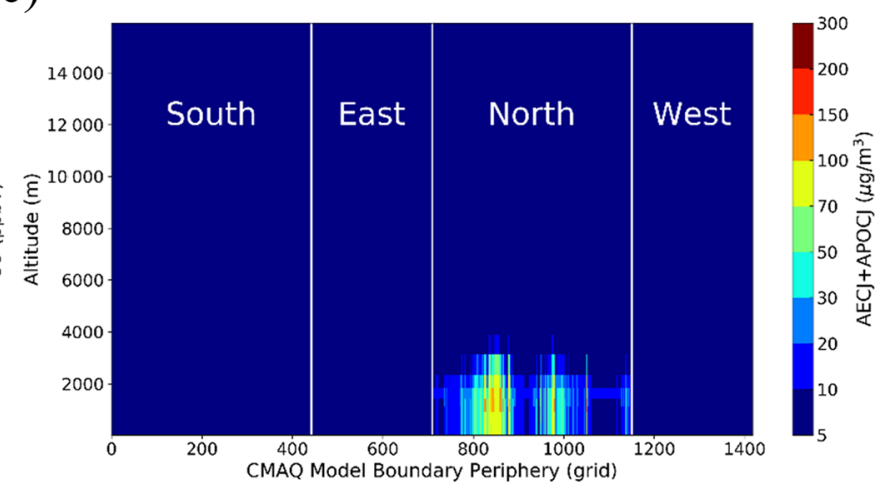

(d)

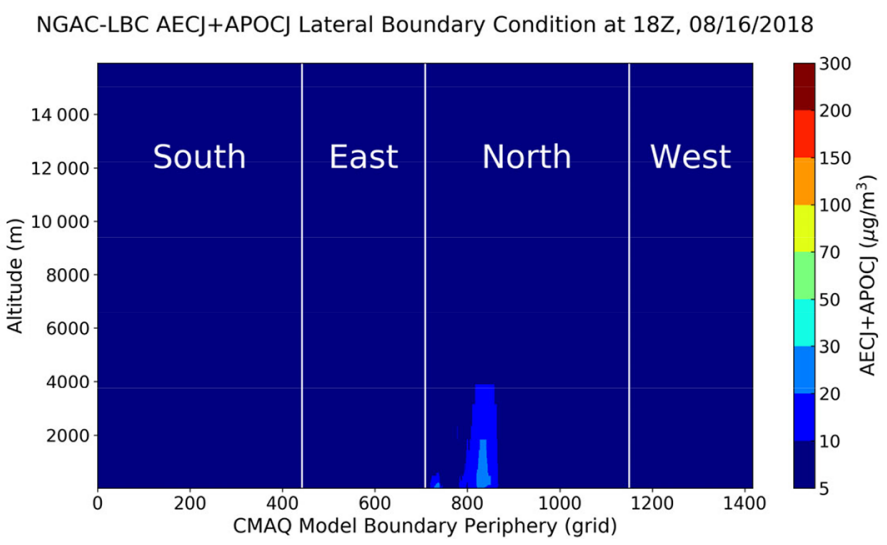

Figure 12. VIIRS-AOT (a) on 16 August 2018 and the corresponding derived AOT-NLBC for CO (b) and AECJ + APOCJ (c). Plot (d) shows NGAC-LBC's AECJ + APOCJ at the same time. 
(a) CMAQ_Base Predicted $\mathrm{O}_{3}$ at $18 \mathrm{Z}, 08 / 17 / 2018$

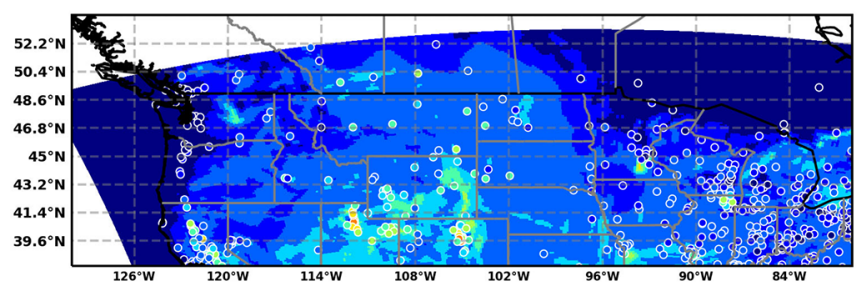

(c) AOT-NLBC Predicted $\mathrm{O}_{3}$ at $18 \mathrm{Z}, 08 / 17 / 2018$

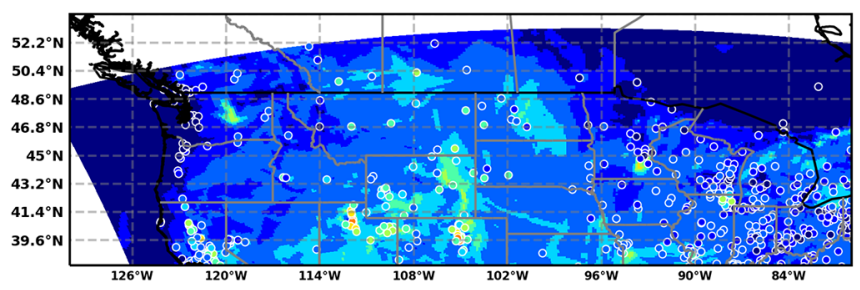

(e) NGAC_LBC Predicted $\mathrm{O}_{3}$ at $18 \mathrm{Z}, 08 / 17 / 2018$
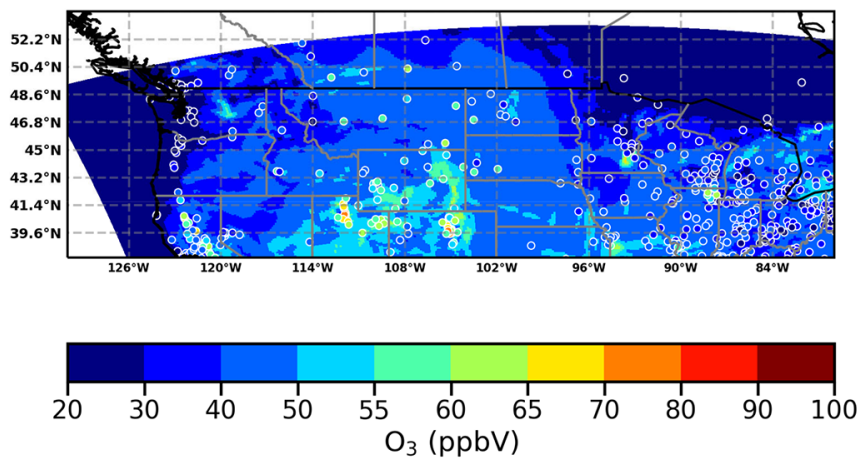

(b) CMAQ_Base Predicted PM2.5 at 18Z, 08/17/2018

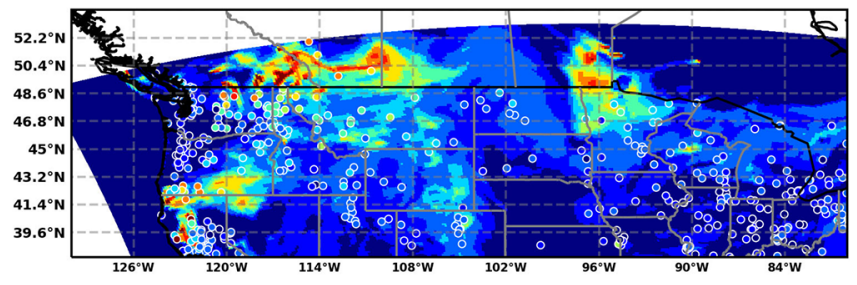

(d) AOT-NLBC Predicted PM2.5 at 18Z, 08/17/2018

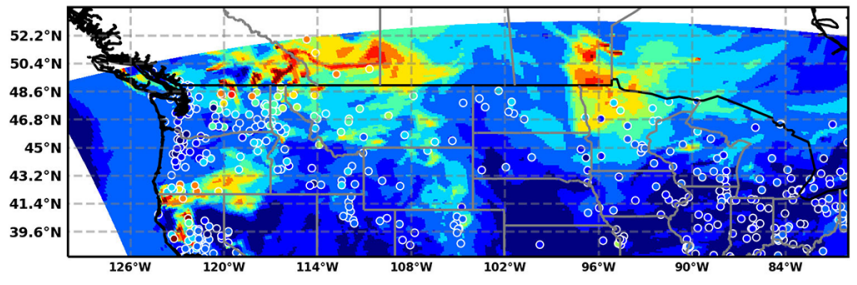

(f) NGAC-LBC Predicted PM2.5 at 18Z, 08/17/2018
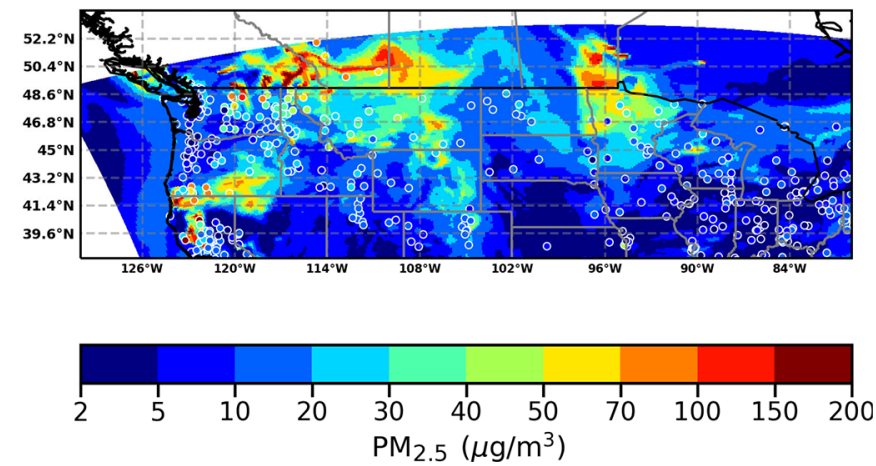

Figure 13. Model-predicted surface ozone (a, c, e) and $\mathrm{PM}_{2.5}(\mathbf{b}, \mathbf{d}, \mathbf{f})$ with CMAQ_Base (a, b), AOT-NLBC (c, d), and NGAC-LBC (e, f) for 17 August 2018 (the colored circles show the AIRNow observations). Please note that the dates in this figure are given in the format of month day year (mm/dd/yyyy). This figure is plotted using cartopy https://scitools.org.uk/cartopy/docs/latest/ (last access: February 2021), which uses the national and state border information from http://www.naturalearthdata.com/ (last access: February 2021). Please note that the above figure contains incomplete US state borders.

gust 2018, the impacts of AOT-NLBC on ozone could still reach about 5 ppbv, and the derived CLBCs generally improved the ozone prediction over that region. It implies that long-lived wildfire pollutants, such as $\mathrm{CO}$, could be transported to the farther downwind areas and impact ozone concentrations. Throughout this period, the ozone differences between NGAC-LBC and CMAQ_Base were very small, mainly caused by the aerosols' effect on the photolysis rates.

For $\mathrm{PM}_{2.5}$ concentration, the CMAQ_Base run systematically underpredicted all four EPA regions as shown in Fig. 14, especially over region 10 , as the northwestern states encountered the major wildfire inflow. AOT-NLBC and NGAC-LBC had similar performance over the northern states (i.e., regions 8,10 , and 5), while improving the predictions by reducing the mean bias up to $10 \mu \mathrm{g} \mathrm{m}^{-3}$ over region 10 (Fig. 14d). In region 9, however, they showed some differences in temporal variability (Fig. 14h), as AOT-NLBC only changed the northern boundary. AOT-NLBC overpredicted $\mathrm{PM}_{2.5}$ during 21-23 August 2018, and NGAC-LBC yielded higher $\mathrm{PM}_{2.5}$ after 25 August over region 9. Even though AOT-NLBC only changed the northern boundary conditions, CLBCs could influence the whole domain during the strong intrusion events. The domain-wide statistics of surface $\mathrm{PM}_{2.5}$ predictions are $R$ values of $0.39,0.45$, $0.50 ; \mathrm{MB}$ values of $-7.53,-2.33,-2.70$; and RMSE values of 25.12, 24.04, 22.93 for the CMAQ_Base, NGAC-LBC, and AOT-NLBC runs, respectively. AOT-NLBC had the best overall scores, except that NGAC-LBC had a slightly better mean bias with its dynamic four boundaries.

These results demonstrate that the alternative CLBCs derived from VIIRS AOT may be useful for capturing the key intrusion signals in cases when the CLBCs of global mod- 

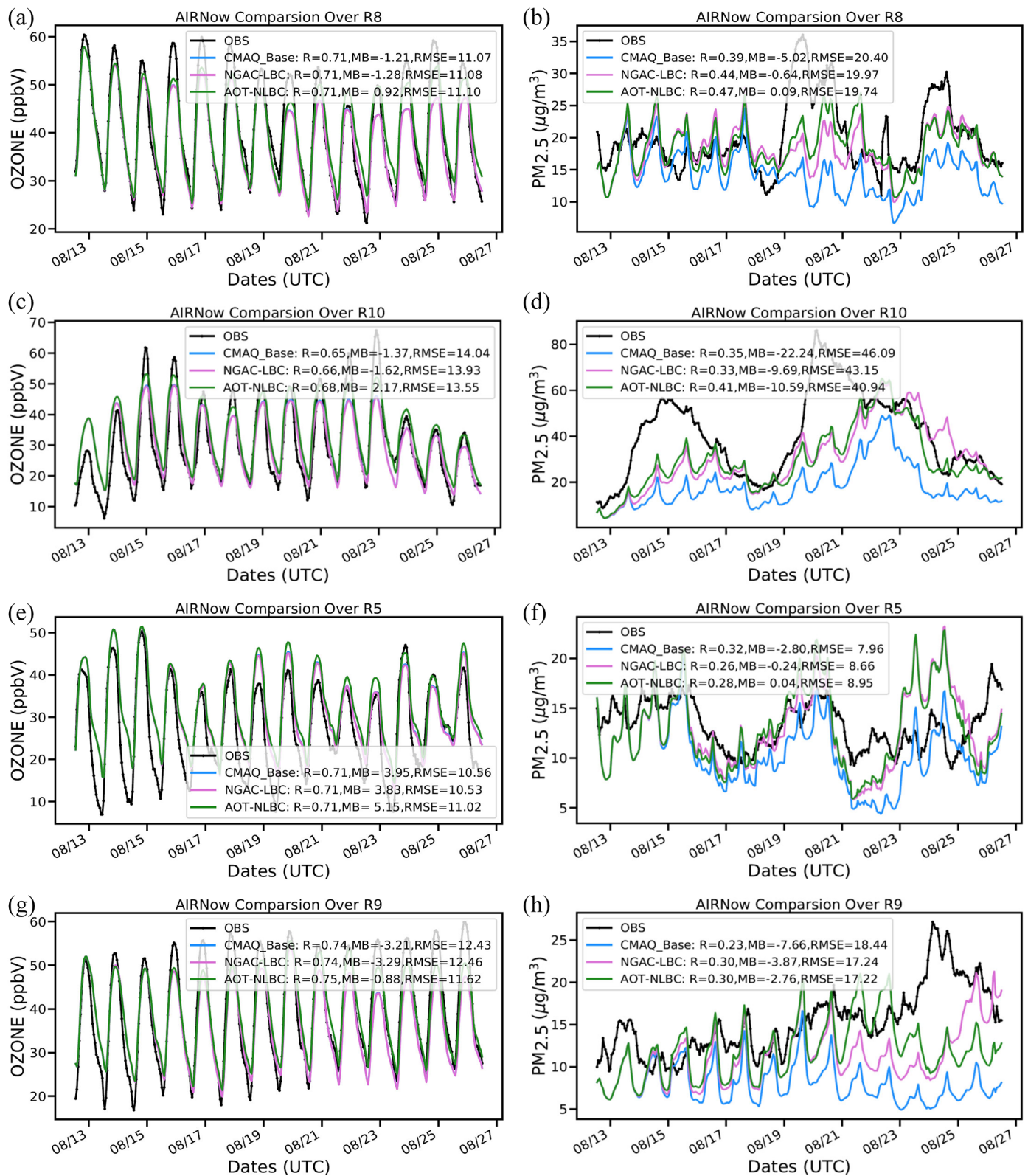

Figure 14. AIRNow time-series comparisons for surface ozone (a, c, e, $\mathbf{g}$ ) and $\mathrm{PM}_{2.5}(\mathbf{b}, \mathbf{d}, \mathbf{f}, \mathbf{h})$ over EPA region 8 (R8, states of Montana, North Dakota, South Dakota, Wyoming, Colorado, and Utah), region 10 (R10, states of Washington, Idaho, and Oregon), region 5 (R5, states of Minnesota, Wisconsin, Illinois, Indiana, Michigan, and Ohio), and region 9 (R9, states of California, Nevada, and Arizona) predicted by CMAQ_Base, NGAC-LBC, and AOT-NLBC in August 2018. Please note that the dates in this figure are given in the format of month day $(\mathrm{mm} / \mathrm{dd})$.

els are not available. This approach is useful in atmospheric composition forecasting, as the satellite AOT retrievals can be obtained in near real time. The wildfire events of summer 2015 and 2018 are similar, which makes the quantitative derivation of CLBCs possible. However, this method may incur biases, which may be due to two reasons: (1) the relatively low correlation coefficient (Fig. S3) and (2) the lack of detailed information on vertical distribution for the total column loading of pollutants. These factors depend on the chosen database, in this case of summer 2015, where the major aerosol intrusion occurred below $3 \mathrm{~km}$ (Fig. 7). If other intrusion events have major elevated aerosol signals, the use of the AOT-derived LBC may put too many aerosols in lower layers and cause surface $\mathrm{PM}_{2.5}$ overpredictions. 


\section{Conclusion}

In this study, we examined the influence of CLBCs on the prediction of regional air quality and used surface ozone and $\mathrm{PM}_{2.5}$ observations to verify the impacts. We developed a full-chemistry mapping table from the GEOS global model to CMAQ's CB05-AERO6 species. The simulations with the GEOS dynamic CLBCs performed the best compared with the surface observations in summer 2015 when the Saharan dust and Canadian wildfire intrusion events occurred. The base simulation (CMAQ_Base) had the worst model performance, as it did not account for these external influences. NGAC-LBC only considered the GOCART aerosols (not full chemistry). The simulation with NGAC-LBC demonstrated good performance for capturing the dust storm intrusion but missed the ozone enhancements in the northern USA due to the Canadian fire events. The influences of CLBCs on the model performance depended on not only the distance from the inflow boundary but also the specific species and their regional characteristics, exemplified by the difference distributions of CLBCs' impacts on ozone and $\mathrm{PM}_{2.5}$. During the studied events of summer 2015, the CLBCs affected both $\mathrm{PM}_{2.5}$ mean background concentration and its spatiotemporal variability. The CLBCs' influences on $\mathrm{PM}_{2.5}$ 's correlation coefficient $(R)$ mainly appeared near the inflow boundary and decreased along with the distance from the boundary. The influence of the CLBCs on $\mathrm{PM}_{2.5}$ background concentration, however, could be seen further inside the domain. The CLBCs' influence on ozone was more complex and affected both by the boundary inflows of ozone and/or its precursors, as well as downward transport from the upper troposphere and stratosphere. In this study, only the aerosol dynamic CLBCs (GEOS-LBC or NGAC-LBC) showed the impacts on the model spatiotemporal variability, while the static CLBCs mainly impacted the background concentrations and mean bias. It should be noted that this study mainly focused on the CLBCs' influence on surface sites. For elevated observational platforms, such as airborne measurements, the spatiotemporal variability of the CLBCs may also affect the three-dimensional ozone model performance due to the relatively fast transport and weak local ozone production in the upper layers (Tang et al., 2007).

The AOT-derived CLBCs for the northern boundary (AOTNLBC) demonstrated that it could be used as an alternative method to capture intrusion events when the dynamic CLBCs from global models are not available. Although the VIIRS AOT was updated only once per day and the CLBCs derived from it had a relatively noisy spatial distribution, this method still showed its value to replace the static CLBCs in a nearreal-time air quality forecast. For the wildfire intrusion events of summer 2018, AOT-NLBC showed generally better model performance than NGAC-LBC. It should be cautioned that using this method may lead to biases stemming from the discrepancies in AOT regression or inconsistent representations of the timing or vertical distributions of atmospheric pollu- tants between the actual events and the database events used in the derivation. It should be noted that other indicators, such as surface monitoring data, can be also used to derive the similar CLBCs if the historical CLBCs have a good correlation with these data, and there is a relatively dense number of stations available near the inflow boundary. Geostationary satellites can also achieve a near-real-time AOT retrieval with a high temporal resolution (on the order of minutes), which will likely provide a better solution for the fast capturing of the intrusions that vary significantly in space and time. Currently, the main issue for using geostationary AOT is their relatively poor retrieval quality in high latitudes or under high zenith angles. As such issues become alleviated, geostationary AOT retrievals may be used as an indicator to derive the CLBCs or even replace the CLBCs provided by the global models.

Code availability. The source code used in this study is available online at https://github.com/NOAA-EMC/EMC_aqfs (last access: 4 May 2020), https://doi.org/10.5281/zenodo.4543694 (Huang et al., 2021).

Data availability. The VIIRS AOT data used here are at https://doi.org/10.7289/V5319T4H (Kondragunta et al., 2021). The surface AIRNow monitoring data can be obtained via https://airnow. gov (last access: 4 May 2020) (US EPA, 2020).

Supplement. The supplement related to this article is available online at: https://doi.org/10.5194/acp-21-2527-2021-supplement.

Author contributions. YT conducted the model run, writing, visualization, conceptualization, methodology, analysis, and investigation. HB and LDO provided GEOS global model data and helped with the writing. ZT and DT coordinated this project with funding and conceptualization and revised the paper. PL, JM, and IS provided the computing resources and supervision. PCC helped revise the paper. BB helped with the visualization and analysis. LP provided the model input data. CHL and JW provided the NGAC output.

Competing interests. The authors declare that they have no conflict of interest.

Acknowledgements. This research was supported by the National Oceanic and Atmospheric Administration (NOAA) under the Weather Program Office (funding no. NA16OAR4590118) and the NOAA National Air Quality Forecast Capability (grant no. T8MWQAQ). We thank the NASA MAP program and NASA Center for Climate Simulation for support of the GEOS GMI model and NASA Health and Air Quality program for supporting NAQFC satellite applications. The surface AIRNow observations are pro- 
vided by the US EPA, and satellite data are produced by NASA and NOAA.

Financial support. This research has been supported by the National Oceanic and Atmospheric Administration (grant no. NA16OAR4590118) and the National Oceanic and Atmospheric Administration (grant no. T8MWQAQ).

Review statement. This paper was edited by Kostas Tsigaridis and reviewed by two anonymous referees.

\section{References}

Appel, K. W., Roselle, S. J., Gilliam, R. C., and Pleim, J. E.: Sensitivity of the Community Multiscale Air Quality (CMAQ) model v4.7 results for the eastern United States to MM5 and WRF meteorological drivers, Geosci. Model Dev., 3, 169-188, https://doi.org/10.5194/gmd-3-169-2010, 2010.

Arlander, D. W., Brüning, D., Schmidt, U., and Ehhalt, D. H.: The tropospheric distribution of formaldehyde during TROPOZ II, J. Atmos. Chem., 22, 251-269, 1995.

Bey, I., Jacob, D. J., Logan, J. A., and Yantosca, R. M.: Asian chemical outflow to the Pacific in spring: origins, pathways, and budgets, J. Geophys. Res., 106, 23097-23113, 2001.

Bian, H., Chin, M., Hauglustaine, D. A., Schulz, M., Myhre, G., Bauer, S. E., Lund, M. T., Karydis, V. A., Kucsera, T. L., Pan, X., Pozzer, A., Skeie, R. B., Steenrod, S. D., Sudo, K., Tsigaridis, K., Tsimpidi, A. P., and Tsyro, S. G.: Investigation of global particulate nitrate from the AeroCom phase III experiment, Atmos. Chem. Phys., 17, 12911-12940, https://doi.org/10.5194/acp-1712911-2017, 2017.

Carlton, A. G., Bhave, P. V., Napelenok, S. L., Edney, E. D., Sarwar, G., Pinder, R. W., Pouliot, G. A., and Houyoux, M.: Model representation of secondary organic aerosol in CMAQv4.7, Environ. Sci. Technol., 44, 8553-8560, 2010.

Chin, M., Rood, R. B., Lin, S.-J., Muller, J.-F., and Thompson, A. M.: Atmospheric sulfur cycle simulated in the global model GOCART: Model description and global properties, J. Geophys. Res., 105, 24671-24687, https://doi.org/10.1029/2000JD900384, 2000.

Chin, M., Ginoux, P., Kinne, S., Torres, O., Holben, B. N., Duncan, B. N., Martin, R. V., Logan, J. A., and Higurashi, A.: Tropospheric aerosol optical thickness from the GOCART model and comparisons with satellite and Sun photometer measurements, J. Atmos. Sci., 59, 461-483, 2002.

Colarco, P., da Silva, A., Chin, M., and Diehl, T.: Online simulations of global aerosol distributions in the NASA GEOS-4 model and comparisons to satellite and groundbased aerosol optical depth, J. Geophys. Res., 115, D14207, https://doi.org/10.1029/2009JD012820, 2010.

Eastham, S. D., Weisenstein, D. K., and Barrett, S. R.: Development and evaluation of the unified troposphericstratospheric chemistry extension (UCX) for the global chemistry-transport model GEOS-Chem, Atmos. Environ., 89, 52-63, https://doi.org/10.1016/j.atmosenv.2014.02.001, 2014.
Foley, K. M., Roselle, S. J., Appel, K. W., Bhave, P. V., Pleim, J. E., Otte, T. L., Mathur, R., Sarwar, G., Young, J. O., Gilliam, R. C., Nolte, C. G., Kelly, J. T., Gilliland, A. B., and Bash, J. O.: Incremental testing of the Community Multiscale Air Quality (CMAQ) modeling system version 4.7, Geosci. Model Dev., 3, 205-226, https://doi.org/10.5194/gmd-3-205-2010, 2010.

Helmig, D., Petrenko, V., Martinerie, P., Witrant, E., Rockmann, T., Zuiderweg, A., Holzinger, R., Hueber, J., Thompson, C., White, J. W. C., and Sturges, W.: Reconstruction of Northern Hemisphere 1950-2010 atmospheric non-methane hydrocarbons, Atmos. Chem. Phys., 14, 1463-1483, https://doi.org/10.5194/acp14-1463-2014, 2014.

Henderson, B. H., Akhtar, F., Pye, H. O. T., Napelenok, S. L., and Hutzell, W. T.: A database and tool for boundary conditions for regional air quality modeling: description and evaluation, Geosci. Model Dev., 7, 339-360, https://doi.org/10.5194/gmd-7339-2014, 2014.

Huang, J., Lee, P., and Potts, M.: ytangnoaa/EMC_aqfs: NAQFC with CMAQ 5.0.2 (Version v5.1.0), Zenodo, https://doi.org/10.5281/zenodo.4543694, 2021.

Janach, W. E.: Surface ozone: trend details, seasonal variations, and interpretation, J. Geophys. Res.-Atmos., 94, 18289-18295, 1989.

Kondragunta, S., Laszlo, I., and Ma, L.: JPSS Program Office (2017): NOAA JPSS Visible Infrared Imaging Radiometer Suite (VIIRS) Aerosol Optical Depth and Aerosol Particle Size Distribution Environmental Data Record (EDR) from NDE, NOAA National Centers for Environmental Information, https://doi.org/10.7289/V5319T4H, 2021.

Lee, P., McQueen, J., Stajner, I., Huang, J., Pan, L., Tong, D., Kim, H.-C., Tang, Y., Kondragunta, S., and Ruminski, M.: NAQFC developmental forecast guidance for fine particulate matter $\left(\mathrm{PM}_{2.5}\right)$, Weather Forecast., 32, 343-360, https://doi.org/10.1175/waf-d-15-0163.1, 2017.

Lu, C.-H., da Silva, A., Wang, J., Moorthi, S., Chin, M., Colarco, P., Tang, Y., Bhattacharjee, P. S., Chen, S.-P., Chuang, H.-Y., Juang, H.-M. H., McQueen, J., and Iredell, M.: The implementation of NEMS GFS Aerosol Component (NGAC) Version 1.0 for global dust forecasting at NOAA/NCEP, Geosci. Model Dev., 9, 19051919, https://doi.org/10.5194/gmd-9-1905-2016, 2016.

Molod, A., Takacs, L., Suarez, M., Bacmeister, J., Song, I.-S., and Eichmann, A.: The GEOS Atmospheric General Circulation Model: Mean Climate and Development from MERRA to Fortuna, Technical Report Series on Global Modeling and Data Assimilation, NASA/TM-2012-104606/Vol. 28, Goddard Space Flight Center,Greenbelt, Maryland, USA, available at: http://citeseerx.ist.psu.edu/viewdoc/download?doi=10.1. 1.498.8543\&rep=rep1\&type=pdf (last access: February 2021), 2012.

Pan, L., Tong, D., Lee, P., Kim, H. C., and Chai, T.. Assessment of $\mathrm{NO}_{x}$ and $\mathrm{O}_{3}$ forecasting performances in the US National Air Quality Forecasting Capability before and after the 2012 major emissions updates, Atmos. Environ., 95, 610-619, 2014.

Pan, L., Kim, H., Lee, P., Saylor, R., Tang, Y., Tong, D., Baker, B., Kondragunta, S., Xu, C., Ruminski, M. G., Chen, W., Mcqueen, J., and Stajner, I.: Evaluating a fire smoke simulation algorithm in the National Air Quality Forecast Capability (NAQFC) by using multiple observation data sets during the Southeast Nexus (SENEX) field campaign, Geosci. Model Dev., 13, 21692184, https://doi.org/10.5194/gmd-13-2169-2020, 2020. 
Pierce, T., Geron, C., Bender, L., Dennis, R., Tonnesen, G., and Guenther, A.: Influence of increased isoprene emissions on regional ozone modeling, J. Geophys. Res., 103, 25611-25629, 1998.

Mathur, R., Xing, J., Gilliam, R., Sarwar, G., Hogrefe, C., Pleim, J., Pouliot, G., Roselle, S., Spero, T. L., Wong, D. C., and Young, J.: Extending the Community Multiscale Air Quality (CMAQ) modeling system to hemispheric scales: overview of process considerations and initial applications, Atmos. Chem. Phys., 17, 12449-12474, https://doi.org/10.5194/acp-17-124492017, 2017.

Sarwar, G., Luecken, D., and Yarwood, G.: Chapter 2.9 Developing and implementing an updated chlorine chemistry into the community multiscale air quality model, in: Air Pollution Modeling and Its Application XVIII, vol. 6 of Developments in Environmental Science, edited by: Borrego, C. and Renner, E., Elsevier, Amsterdam, the Netherlands, 168-176, https://doi.org/10.1016/S1474-8177(07)06029-9, 2007.

Sillman, S., He, D., Cardelino, C., and Imhoff, R. E.: The use of photochemical indicators to evaluate ozone- $\mathrm{NO}_{x}$-hydrocarbon sensitivity: Case studies from Atlanta, New York, and Los Angeles, J. Air Waste Manage. Assoc., 47, 1030-1040, 1997.

Sonntag, D. B., Baldauf, R. W., Yanca, C. A., and Fulper, C. R.: Particulate matter speciation profiles for light-duty gasoline vehicles in the United States, J. Air Waste Manage. Assoc., 64, 529-545, https://doi.org/10.1080/10962247.2013.870096, 2014.

Strode, S. A., Ziemke, J. R., Oman, L. D., Lamsal, L. N., Olsen, M. A., and Liu, J.: Global changes in the diurnal cycle of surface ozone, Atmos. Environ., 199, 323-333, https://doi.org/10.1016/j.atmosenv.2018.11.028, 2019.

Tanaka, P. L., Allen, D. T., McDonald-Buller, E. C., Chang, S., Kimura, Y., Mullins, C. B., Yarwood, G., and Neece, J. D.: Development of a chlorine mechanism for use in the carbon bond IV chemistry model, J. Geophys. Res.-Atmos., 108, 4145, https://doi.org/10.1029/2002JD002432, 2003.

Tang, Y., Carmichael, G. R., Thongboonchoo, N., Chai, T., Horowitz, L. W., Pierce, R. B., Al-Saadi, J. A., Pfister, G., Vukovich, J. M., Avery, M. A., Sachse, G. W., Ryerson, T. B., Holloway, J. S., Atlas, E. L., Flocke, F. M., Weber, R. J., Huey, L. G., Dibb, J. E., Streets, D. G., and Brune, W. H.: Influence of lateral and top boundary conditions on regional air quality prediction: a multiscale study coupling regional and global chemical transport models, J. Geophys. Res., 112, D10S18, https://doi.org/10.1029/2006JD007515, 2007.
Tang, Y., Lee, P., Tsidulko, M., Huang, H. C., McQueen, J. T., DiMego, G. J., Emmons, L. K., Pierce, R. B., Thompson, A. M., Lin, H. M., and Kang, D.: The impact of chemical lateral boundary conditions on CMAQ predictions of tropospheric ozone over the continental United States, Environ. Fluid Mech., 9, 43-58, https://doi.org/10.1007/s10652-008-9092-5, 2009.

Tyndall, G. S., Cox, R. A., Granier, C., Lesclaux, R., Moortgat, G. K., Pilling, M. J., Ravishankara, A. R., and Wallington, T. J.: Atmospheric chemistry of small organic peroxy radicals, J. Geophys. Res.-Atmos., 106, 12157-12182, 2001.

Urbanski, S. P., Hao, W. M., and Baker, S.: Chemical composition of wildland fire emissions, Dev. Environ. Sci., 8, 79-107, https://doi.org/10.1016/S1474-8177(08)00004-1, 2008.

US EPA: Real-time surface monitoring data, available at: https:// airnow.gov, last access: 4 May 2020.

Wang, J., Bhattacharjee, P. S., Tallapragada, V., Lu, C. H., Kondragunta, S., da Silva, A., Zhang, X. Y., Chen, S. P., Wei, S. W., Darmenov, A. S., and McQueen, J.: The implementation of NEMS GFS Aerosol Component (NGAC) Version 2.0 for global multispecies forecasting at NOAA/NCEP Part 1: Model descriptions, Geosci. Model Dev., 11, 2315-2332, https://doi.org/10.5194/gmd-11-2315-2018, 2018.

Whitby, E. R. and McMurry, P. H.: Modal aerosol dynamics modeling, Aerosol Sci. Tech., 27, 673-688, 1997.

Whitten, G. Z., Heo, G., Kimura, Y., McDonald-Buller, E., Allen, D. T., Carter, W. P., and Yarwood, G.: A new condensed toluene mechanism for Carbon Bond: CB05-TU, Atmos. Environ., 44, 5346-5355, https://doi.org/10.1016/j.atmosenv.2009.12.029, 2010.

Yarwood, G., Rao, S., Yocke, M., and Whitten, G.: Updates to the Carbon Bond Chemical Mechanism: CB05, Technical Report RT-0400675 ENVIRON, International Corporation Novato, CA, USA, 2005. 